\title{
Towards a Software Tool Supporting Decisions in Planning Heap Revitalization Processes
}

\author{
Andrzej Bialas
}

Citation: Bialas, A. Towards a Software Tool Supporting Decisions in Planning Heap Revitalization Processes. Sustainability 2022, 14 , 2492. https://doi.org/10.3390/ su14052492

Academic Editor: Ewa Ziemba

Received: 20 December 2021

Accepted: 17 February 2022

Published: 22 February 2022

Publisher's Note: MDPI stays neutral with regard to jurisdictional claims in published maps and institutional affiliations.

Copyright: (C) 2022 by the author. Licensee MDPI, Basel, Switzerland. This article is an open access article distributed under the terms and conditions of the Creative Commons Attribution (CC BY) license (https:// creativecommons.org/licenses/by/ $4.0 /)$.
Łukasiewicz Research Network-Institute of Innovative Technologies EMAG, 40-189 Katowice, Poland;
andrzej.bialas@emag.lukasiewicz.gov.pl

Abstract: This paper presents an advanced risk management methodology which supports the planning of the revitalization process of post-mining heaps. More specifically, it supports decisionmakers in the selection of the most advantageous revitalization actions with respect to the defined criteria embracing risk and cost-benefit parameters as well as different qualitative factors. This methodology was elaborated with a view to software implementation and is a good example of ICT adoption in emerging domains of application. The question is how to organize the revitalization decision process and support it with a software tool. The methodology and tool are based on three pillars: risk, cost-benefit, and qualitative criteria assessments of the considered revitalization actions in order to select the target for the implementation of the given heap. This paper presents the methodology implemented in the software as well as its validation on an extensive example. The steps described in the example allow the decision-maker to identify a target revitalization alternative. The conclusions focus on the solution's feasibility and the software implementation and extensions.

Keywords: risk management; cost-benefits analysis; qualitative criteria analysis; post-mining areas revitalization; decision support tool

\section{Introduction}

This paper concerns the adoption of ICT in the revitalization of post-mining heaps and presents a software tool able to support the planning of the revitalization process.

This article is closely related to the EU RFCS SUMAD (Sustainable Use of Mining Waste Dumps) project. The project's goal is focused on exploring the possible uses of areas which consist of coal-mining spoil with respect to geotechnical, sustainability, environmental, socio-economic, and long-term management challenges. This objective will be achieved through the application of risk management and physical or numerical modelling to different revitalization schemes. The core is technical viability for the development of renewable energy infrastructure. The input will come from tip operators, developers, and authorities involved in the project. This way, the undertaken operations will have maximum possible impact. The project concepts will be tested on a case-study site.

SUMAD is an interdisciplinary project [1]. It combines geotechnical engineering, geology, ecology, and IT. The author's organization will provide the software component called SUMAD RMT (Risk Management Tool), whose role is to support decision-makers in planning revitalization processes of post-mining sites, particularly spoil heaps. The aim of this paper is to present the methodology and the general model to be implemented in this software.

The SUMAD project consortium, embracing R\&D institutes and stakeholders from the UK, France, Czech Republic, Poland, and Greece, represents deep knowledge and experience in the heap revitalization domain.

There are many synonyms used in research papers that describe activities aimed at improving the properties of waste dumps, brownfields, etc. The term "revitalization", generally broader than "rehabilitation", is more adequate for describing the activities 
dealing with heap-related risk management in this paper. The heap context is important here, and the issue at hand is: "what could be done with this spoiled ground?". Generally, two options against risks are possible:

- $\quad$ Putting away all spoiled material from the heap, using it elsewhere, and rehabilitating the area where the heap was placed; it is possible to restore (i.e., to revitalize) this area; this option is mentioned (Section 2.2.3 of the paper) as "material utilization"; it is close to the risk management strategy called "risk avoiding";

- Improving the heap in its place, making the heap the least offensive to the people and the natural environment, i.e., returning it to the natural environment and restoring suitable forms of life; in this case, the term "revitalization" is more adequate; this option is mentioned (Section 2.2.3) as "land development"; the heap is left in its place and its quality is improved and well-fitted to natural surroundings; in this case, we focus not only on the quality of the environment and natural balance, but also on the needs of the local community and the business opportunities; revitalization is close to the risk management strategy called "risk mitigation".

Section 1.1 presents the general context of the research and its importance. Section 1.2 discusses and summarizes the current state of the research field. Chapter 2, featuring materials and methods, presents the SUMAD risk management methodology and the general model of the tool (Section 2.1), the knowledge base related to revitalization (Section 2.2), and methodology details (Section 2.3). Chapter 3, discussing the results of the paper, presents an extensive example of the methodology used (validation). Chapter 4 includes the final discussion and conclusions.

\subsection{Research Context and Importance}

Areas and objects degraded by industrial activities, especially mining, constitute a big ecological problem. In particular, they cause risks to human health, the natural environment, and the economy. Their revitalization is difficult and costly, requires coordinated and multidirectional revitalization activities, and has to take into account human factors.

The risks implied by post-industrial objects and areas can be mitigated by the application of different revitalization techniques. They should be suitable for achieving ecological effects and be acceptable from the economic and social points of view. To develop a proper revitalization strategy, one needs deep knowledge about the revitalized object based on experiments and analyses. The analyses are multidirectional; they involve risk factors, financial issues, and social perception. In addition, the decision process is very complicated and should be supported by ICT. Due to these factors, a software tool has been developed. This paper serves as an example of the concept of "ICT Adoption for Sustainability".

The term "sustainability" includes social, economic, and environmental aspects. Sometimes, cultural and political aspects are also distinguished. Generally, societies should meet not only their current needs, but also ensure resources and good living conditions for future generations. Economic growth is important but should be bearable for society and consider environmental protection. All of these aspects are strongly interrelated, and all can be supported by ICT. The adoption of ICT promotes economic, social, and human development, thanks to the available and improved data processing and effective communication abilities.

Research on ICT adoption concerns all of the above-mentioned aspects of sustainability. There are numerous publications in this domain related to particular sustainability dimensions.

An example of research on ICT adoption, mainly from the social perspective, is included in the paper [2]. This research is focused on the contribution of ICT adoption to the sustainability of stakeholders belonging to three groups: enterprises, households, and governmental units in Poland. This paper supplements previous research, which confirms that ICT adoption positively influences ecological, economic, sociocultural, and political sustainability. The presented research is based on survey questionnaires filled in by the representatives of stakeholders. The levels of sustainability achieved from the adoption of 
ICT and the factors influencing the sustainable information within society are discussed and concluded in the paper [2].

Economic sustainability concerns long-term economic growth with no negative impacts on society, environment, culture, etc. An example of research in this area is presented in the paper [3]. The author discusses questionable assumptions and paradigms related to economic growth and presents some best practices that deal with "green growth".

Ecological aspects of sustainability are focused on the protection of the natural environment in harmony with other aspects. Some issues, such as the maintenance or restoration of ecosystems, the diversity of plant and animal communities, the productive capacity of ecological systems, greenhouse gas mitigation, climate change, and renewable energy, have a global character, while others are location-specific, including: soil erosion, water management, soil quality, and air and water pollution. ICT adoption plays an important role in all these issues.

The ecological aspects of sustainability encompass the post-mining heap revitalization issue discussed in this paper. Section 1.3 presents a literature review, including methods, models, and software tools related to ICT adoption for sustainability in the ecological dimension, close to this paper's subject.

The author remarks that the three factors, i.e., risk-related, financial, and social factors, were considered in the European ValueSec and CIRAS projects [4,5], performed earlier by the author's organization. These projects, however, provided solutions for rather different domains of application, i.e., security of public mass events, public mass transportation, air transportation/airport, communal security planning, cyber security, and critical infrastructure protection. For each of these domains of application, tool-based decision frameworks were developed, allowing for the selection of security measures which:

- $\quad$ properly affect the risk;

- $\quad$ have minimal costs and bring maximal benefits;

- have identified restrictions: social, psychological, political, legal, ethical, economical, technical, environmental, etc.

\subsection{Research Motivation and Objectives}

The research objective presented in the paper is in line with one of the project objectives included in the SUMAD project proposal, i.e., "Develop a global risk management tool utilizing information gleaned from throughout entire project". The mentioned information is related to other project objectives, which concern: heap properties across Europe; the geotechnical and environmental assessment of heaps; numerical and physical modelling of spoil material; simulation of the complicated mechanical behavior of spoil material; the design and test of foundation systems; identification of possible revitalization activities with respect to different technical, economic, social, political, etc., constraints; an examination of ground improvement techniques for more sensitive equipment/structures; monitoring techniques to track the behavior of installed infrastructure; and the introduction of the geotechnical reliability concept to address issues related to the heterogeneity and variability present in spoil material, thereby permitting a more accurate geotechnical risk assessment of post-operational works. The SUMAD research problem is interdisciplinary, innovative, and broad, but the assumed tool should play the role of "an integrator" of partial issues.

Considering the quantity and diversity of information in the risk management tool is a challenge and implies that such a tool should be very specific, innovative, and elaborated from scratch. The research motivation is related to this challenge and need for innovativeness; in this respect, there are no ready-made risk management tools that meet the project requirements, which is confirmed by the literature review, to be presented later. It is a chance for the paper's author to contribute to the innovative software developed by the SUMAD project team.

The paper thesis can be expressed based on the above SUMAD objectives.

It is possible to develop a specific SUMAD risk management methodology (a framework), which must be capable of the following: 
- Support decision-makers in the selection of the most advantageous revitalization activities for the given heap;

- Consider different heap properties (geotechnical and environmental), heap-related risk factors, and economic and non-economic constraints;

- Be implemented in software.

This implies the main research questions:

- How can the decision process leading to the selection of the target revitalization activities be structured? How can input information for the decision process be identified? How can decision criteria be defined? How can results of analyses be presented to decision-makers?

- How can heap properties be specified so that they will be necessary and sufficient for analysts to identify risk factors as well as economic and non-economic constraints?

- How can a risk management framework for software developers be specified?

The research objectives are as follows:

- To develop a specific risk management framework to be implemented in software;

- To validate it on a simplified but complete and representative heap example.

The research challenge is to integrate, in a coherent way, several different partial issues into one specific risk management framework.

The author's concept adopts some ideas from the ValueSec/CIRAS projects-by analogy, the SUMAD risk management methodology will be based also on three pillars: risk management, cost-benefit analysis, and "soft factors" analysis. Common risk terminology should be redefined in the SUMAD project domain as well. The revitalized heap and its environment are the central point of consideration, playing the role of "an asset". Revitalization activities play the role of "security measures", which mitigate the negative impact of the heap on the environment and the people. Threats, vulnerabilities, cost-benefit categories, "soft factors" such as social, political, psychological, etc., factors are also considered here, but they have quite a different character from that in the ValueSec/CIRAS methodology.

Based on these results, the author's organization developed SUMAD RMT (Risk Management Tool), identified the domain data in detail, and validated the tool. Other SUMAD project members, as domain experts, delivered domain data for the tool and performed the tool validation on real objects. The SUMAD RMT software is one of the key results of the SUMAD project.

The author's contribution, whose initial results were presented in the papers [6,7], is focused on adopting the ValueSec/CIRAS methodology to a new domain of application, i.e., the revitalization of post-mining heaps. This idea was included in the SUMAD project, which is the foundation for the SUMAD RMT implementation.

\subsection{Current State of the Research Field}

Considering the domain of application, i.e., the revitalization of post-mining heaps, the SUMAD methodology requires a specific, interdisciplinary approach to risk management, including technical, ecological, and geotechnical issues.

SUMAD should provide feasible revitalization plans embracing realistic revitalization techniques, i.e., properly reducing risk caused by the degraded objects that is economically effective and free of different non-financial constraints. This means that the risk management methodology is extended by the cost-benefit analysis and the qualitative analysis focused on soft factors and decision support.

All these issues are considered in a literature review, which includes heap revitalization or similar issues.

The continuous process of risk management combines the identification, analysis, and assessment of potential hazards in a system or hazards related to a certain activity, risk monitoring, and communication. The standard ISO31000 [8] defines a general risk management framework. 
The first step is to recognize the risk picture, which becomes the basis for risk control measures proposed to eliminate or reduce the potential harm to people, the environment, or other assets. Risk management methodologies are very diverse and applied in many domains. Some application domains have developed their own methods and tools. Risk management methodologies and tools are taken up by current R\&D projects on the national and international levels, including the EU level. Apart from that, the following sources provide comprehensive reviews of $R \& D$ results in this area:

- IEC 31010 standard [9], describing about 30 recognized risk assessment methods for different applications;

- $\quad$ ENISA website [10], including an inventory of risk management/assessment methods, mostly ICT-focused; different risk assessment methods are grouped into three big categories: qualitative, semi-qualitative, and quantitative methods;

- The extensive monograph in [11], featuring the risk management issue in a very comprehensible way; the most representative methods and tools are discussed;

- The extensive monograph in [12], presenting the information security risk management process, based on the general risk management framework (ISO31000) example;

- Appendix $\mathrm{C}$ of the publication [13], providing a comparison between 22 commonly used risk analysis methods.

The above methodologies were the basis for the elaboration of the SUMAD risk management methodology discussed in this paper.

The risks identified for the SUMAD project are caused by natural events (flooding, extreme weather conditions, etc.), technology, practices, processes, products, agents (chemical, biological, radiological, etc.), and industrial activities that may influence ecosystems, animals, and people. Therefore, they are, in fact, ecological risks. The assessment of ecological risks is based on a critical review featuring available data for the identification and quantification of risks associated with a potential threat [14].

Two kinds of analytical tools useful in environmental management, i.e., life cycle assessment (LCA) and risk assessment (RA), are discussed by the authors of [15]. LCA considers the product interaction with the environment at different product life stages. RA considers risks related to the life cycle of a given product. The research is oriented towards the Eco-Management and Audit Scheme (EMAS) needs. Risk assessment is focused on revealing the information about the likelihood, severity, and consequences of potential ecological threats. The paper discusses different LCA and RA tools used in ecology and their integration. The authors omit financial and non-financial factors in risk management, which are of key importance in SUMAD.

The guidelines elaborated by the U.S. Environmental Protection Agency (EPA) [16] were prepared during a period of increasing interest in ecological risk assessment and reflect input from many sources, both within and outside the EPA Agency. The Guidelines expand upon and replace the previously published EPA report Framework for Ecological Risk Assessment (EPA/630/R-92/001, February 1992), which proposed principles and terminology for the ecological risk assessment process.

The ecological risk assessment process is based on two major elements: characterization of effects and characterization of exposure. These focus on conducting the three phases of risk assessment: problem formulation, analysis, and risk characterization.

The TRIAD approach [17] deals with the revitalization of different sites located in the USA. According to the primer for the redevelopment of brownfield sites [18] (p. 15), TRIAD is a dynamic, collaborative approach to site characterization and cleanup. It helps site stakeholders work toward a cleanup that is faster, better, and cheaper and sets the stage for appropriate redevelopment. The goal of the TRIAD approach is to manage decision uncertainty, that is, to increase confidence that project decisions (about contaminant presence, location, fate, exposure, and risk reduction choices and design) are made correctly and cost-effectively [19]. The TRIAD approach minimizes the likelihood of mistakes by cost-effectively supporting the development of an accurate conceptual site model (CSM). Briefly, a CSM is any graphical or written representation (or "conceptualization") of site 
contamination concerns: how it got there, whether or not it is migrating or degrading, how variable concentrations are across the site, what receptors might be exposed, and what risk-reduction strategies are most feasible [18].

The authors of [20] present a framework for the identification of risk factors in brownfield redevelopment. The following categories of factors are considered: technical risks, economic and political, environmental, managerial, and financial factors. These categories include risk cases, which can be considered in the heap revitalization domain as well.

The authors of [21] also present a framework. It is focused on the preliminary risk assessment before brownfield redevelopment. The framework is focused on the complex hazards and environmental legislation. Sixty-five potential hazards were identified from a comprehensive literature review. They were assessed by domain experts with the use of questionnaires and statistical methods. The obtained results allowed for the definition of the framework, which could assist professionals in conducting a preliminary assessment of brownfield sites. The framework allows them to get informative and rapid guidance on any potential liabilities or risks related to a site's suitability for acquisition or redevelopment. The SUMAD framework is focused on comprehensive analyses in the specific domain (heaps).

The researchers in [22] present results of an extensive review of the state-of-the-art models developed for ecological risk assessment (ERA). ERA is focused on the assessment of the environmental effects of certain stressors that lead to immediate or long-term damage or even irreversible harm to an ecosystem. In this domain, "risk" is generally understood as a combination of the probability of the occurrence of a hazardous event and the severity of damage or ill health that can be caused by that event. The basic categories of the considered models are: food-web, ecosystem-based, socio-ecological. They are sometimes very detailed. Risk assessment involves risk estimation, prediction, communication, and decision making. These differ from the approach proposed in the paper.

The background against which ecological risk assessment and management has been developed is discussed along with recent trends in the development of risk assessment and management frameworks documented in the [23]. Seven frameworks from five different countries were examined there. All of them are important for science, suggest adaptive approaches to decision making, and have well-defined analytical steps. Differences in approaches toward the separation of policy and science, the preference for management over assessment, the inclusion of stakeholders, the iterative nature of the analytical cycle, the use of decision criteria, and economic information suggest the considerable evolution of framework design over time.

The authors of [24] review the development of the ecological risk assessment paradigm in the United States, identify ways in which it is being applied and adapted in other countries, explore future research needs and practice improvements, and examine the current issues that need to be considered in taking forward the scientific development of ecological risk assessment as a useful environmental management tool.

The article [25] describes the analysis of theoretical and applied aspects of ecological risk management in terms of coal mining and processing companies, as well as assigns and solves tasks on the identification of ecological risks, assessment of the probability of undesired events, determination of the structure of probable damage, assessment of risk, the estimation of technological and organizational methods and measures of influence on ecological risk in order to reduce and avoid it, and decision making on the practical introduction of particular risk management and control measures.

The authors of the paper [26] discuss risk methods applied during the revitalization of urban areas.

The book [27] is a very comprehensive source of knowledge that deals with ecological risk management. The considered thematic scope is broad: from the permitted release of chemicals, effluents, wastes, new organisms; through items in international trade (e.g., genetically modified crops); the limitation of loading, remediation, and restoration; permitting and managing land use; up to the management of species. This book does not 
concern the revitalization of heaps directly, but it can be very useful for future users of SUMAD RMT, when they decide to investigate very specific ecological issues or develop revitalization plans.

In the book [28], the state of the art of environmental risk management is presented. It describes contaminated site remediation and used technologies, the in situ remediation of a reactor, natural attenuation in contaminated soil remediation, ecoengineering tools, biodegradation-based and other remediation technologies (physical, chemical, electrochemical, nanotechnology-related), and remediation management. The book is focused on technical issues. Certain remediation technologies, specified in the book, are also considered for heaps in the SUMAD project.

Geotechnical risk is related to the ground and represents probable phenomena which may have adverse impacts on the projects. An example of the methodology is specified in the Swedish Report [29]. This methodology, after adaptation, can be used as guidelines in SUMAD.

The authors of [30] discuss the impact of subsoil condition on a constructed object with the risk/opportunity management view.

The objective of this paper [31] is to summarize the outcomes of I2Mine (FP7 Intelligent Deep Mine of the Future) and DynaMine in order to formulate a risk concept suitable for real-time analysis and to produce a tangible measure of the risk levels. The long-term goal is to develop a real-time risk management concept for intelligent deep mines. In this paper, the Fault Tree-Event Tree methodology is proposed, and an example is worked out using strainburst as a sample risk case.

The decision support tool for the waterfront revitalization oriented towards tourism is presented in [32]. The research was aimed at identifying the most potential waterfront typology in this tourism attraction and developing the waterfront sustainable revitalization (SWR) index assessment model. This index can be used by policy makers and urban developers to analyze heritage waterfronts using the Analytical Hierarchy Process (AHP) method. The authors provide an extensive review of multi-criteria decision-making (MCDM) methods-candidates for waterfront revitalization assessment. They did not find any relevant waterfront revitalization decision support tools to evaluate and quantify the capabilities for attracting tourists using the AHP method. They developed their own AHPbased method. The authors considered six types of waterfronts, identified factors relevant to the tourist attraction, performed assessment, and calculated the SWR index. SUMAD RMT is also designed for a specific domain of application (heaps), which differs from the one above. A certain analogy to QCA assessment exists (criteria), but the methods are different. The method in [32] does not consider risk factors and financial factors. SUMAD RMT provides aggregated information for decision-makers who elaborate their decisions manually. It is possible to use MCDM methods to support decisions in a more advanced way, but it is currently out of the project scope.

The authors of [33] consider different kinds of risks related to the restoration of continuous surface lignite mines entering the closure phase. They consider alternative restoration technologies and investigate their various environmental, technical, economic, and social parameters. The decision-making process is based on a multi-criteria methodology embracing the analytical hierarchy process (AHP) to quantify risk factors and the Technique for Order of Preference by Similarity to Ideal Solution (TOPSIS) to rank restoration alternatives based on a low-risk approach.

The authors of [34] report their research dealing with the rehabilitation of western Macedonia lignite mines using the PEST method, which considers political, economic, social, and technological factors. The research focuses on the following land use cases: urban and industrial development, green houses, and industrial heritage parks. The optimization algorithm was elaborated to determine the mix of land uses that maximize revenue, equity, and natural conservation, and minimize investment. Generally, the authors analyzed the pros and cons of particular land use considered for the revitalized object. 
The paper [35] focuses on PV installations in abandoned mines. The research concerns criteria for selecting sites for such an application. The criteria include different environmental, technical, and economic factors. This paper is closely related to the SUMAD project. The research shows that this is one of the best solutions from the environmental and economical perspective.

Sustainable Management Approaches and Revitalization Tools-electronic (SMARTe) [36,37] is a web-based, open source, decision support tool be used by brownfield revitalization stakeholders. SMARTe is related to the bilateral (USA-Germany) ecological initiative, with EPA participation. It can be used to develop and evaluate future reuse scenarios for potentially contaminated sites. SMARTe includes:

- A tool box that includes stand-alone analysis tools and checklists for different revitalization aspects;

- An "eDocument", providing different kinds of information relevant to revitalization, e.g.,: visioning/planning, environmental risk management, social acceptance, and economic viability;

- A search engine;

- The "My project" component, which includes a decision support system that helps the users evaluate and assess the costs and benefits of potential reuse options and helps them to develop a revitalization plan.

SMARTe is a mature tool which can be used in different brownfield revitalizations, but SUMAD is designed for specific task-heap revitalization.

The authors of [38] present risk management in the sustainable development of cities. The article presents an approach based on the Analytic Network Process (ANP) and Political, Economic, Social, and Technological (PEST) criteria.

The cost-benefit assessment methodology (CBA) is a systematic approach that has been applied in business and economy for years. It allows for an estimation of the strengths and weaknesses of alternative solutions, actions, requirements, etc. This technique enables the identification of options for a given application domain, making it possible to work out the best approach for the domain, i.e., the one with biggest benefits in terms of labor, time, cost savings, etc. [39]. The purpose of CBA is to calculate the costs and benefits of different options and to compare the results in order to arrive at the right decision. The decision may concern, particularly, the countermeasures selection during the risk management process.

The cost-benefit and qualitative criteria issues, with respect to the selection of security measures, were initially discussed in $[40,41]$ within the ValueSec project.

Out of the reviewed approaches, there is not a single one that would consider three kinds of factors: mixed-risk, financial, and non-financial factors, and none would be focused on the revitalization of the post-mining waste dumps. Ecological and geotechnical methodologies, research, and experiments carried out by the SUMAD consortium will provide domain data for the tool to predefine threats, vulnerabilities, scenarios, risk measures, and revitalization techniques. The most similar toolset to SUMAD RMT is SMARTe, but it is not focused on the very specific domain of heap revitalization.

\section{SUMAD Risk Management Methodology and Concept of Its Software Implementation}

\subsection{Methodology and Concept of SUMAD RMT}

The character of the methodology is implied by problems related to the heap revitalization process.

1. Heaps may cause many kinds of risks to their environment, especially to people living in the surrounding areas. These risks should be properly analyzed and mitigated by proper revitalization activities. To perform this task, a special software module called RRA (Risk Reduction Assessment) will be developed. RRA is able to elaborate a comprehensive risk picture related to the heap before revitalization actions (called inherent risk) and after them (called residual risk). 
2. Heaps generate different costs but sometimes, especially after their revitalization, also certain benefits. To assess the financial aspects of the revitalization process, a special analytic module, called here the CBA (Cost-Benefit Assessment), is planned. The CBA module will allow for the specification of several financial parameters related to the heap before and after revitalization actions and for the calculation of basic indicators for the purpose of assessing the revitalization investment efficiency, such as the NPV, IRR.

3. Generally, heaps are cumbersome for the environment and for people living in surrounding areas. Many diversified issues are hard to express as risk or financial categories. These issues have a social, political, and psychological, character, among others. To capture these issues and to predict their negative or sometimes positive impact, the QCA (Qualitative Criteria Assessment) module will be elaborated. The QCA module will allow for the identification of non-financial factors related to the heap before and after revitalization actions.

4. To perform the above-mentioned, complex, multidirectional analyses (RRA, CBA, QCA), the tool should be able to specify detailed characteristics of different kinds of heaps. For this reason, the HP (Heap Properties) module is designed. The HP includes the extensive and diversified set of parameters characterizing the revitalized object and its environment (localization, owners, morphology, geology, pollutants, etc.), ensuring input for other modules.

5. During the revitalization process, the package of diversified ERTs (Elementary Revitalization Techniques) should be applied. The issue is how to identify this package, which should be the most advantageous for the given heap and should meet different stakeholders' requirements. This package expresses activities applied to achieve the assumed revitalization effects with respect to the planned land use, risks, costs, benefits, and different constraints. Decision-makers can define several packages of ERTs called Revitalization Alternatives (RVAs) in this paper. These RVAs are subjects of the RRA, CBA, and QCA analyses. To properly manage RVAs, RAC (Revitalization Alternative Composer) is designed. RAC allows for the specification of the initial set of revitalization techniques, usually applied ad hoc before the officially planned revitalization process begins (called "zero" alternative RVA (0)), and the specification of several Revitalization Alternatives RVA(1 .. N-1), which are the subject of multidirectional analyses, in order to select the most advantageous among them for implementation (target RVA).

6. The number of terms related to the analyses that lead to the selection of the target RVA (threats/hazards, vulnerabilities, consequences, Elementary Revitalization Techniques, cost-benefit categories, QCA categories) is huge, and it would be very troublesome for decision-makers to define them ad hoc. For this reason, a knowledge base comprising a coherent and categorized set of terms related heap revitalization is developed. This knowledge base is managed by the PDM (Predefined Data Manager). The PDM maintains a common set of predefined data for any revitalization project to be shared with other modules while the revitalization plan is elaborated. It plays the role of the project domain knowledge base.

7. The results obtained from RRA/QCA/CBA analyses are relatively complicated. They should be aggregated and properly presented to decision-makers. This is ensured by the DMAV (Data Management, Aggregation, and Visualization) software module. DMAV supports decision-makers by presenting ordered information as the input to making decision-related RVA selection for the implementation and generation of the revitalization plan.

8. Assessments of risk factors (likelihood, consequences) during the risk analysis (RRA) are burdened by uncertainty. To reduce this uncertainty and to raise the accuracy of the analyses, a historical database that includes past heap incidents may be very helpful. This role is played by the HEIR (Heap-related Events and Incidents Registration) facility. HEIR allows the registration of any historical data related to different 
heaps in the world, especially the revitalized ones. When the given risk scenario $<$ threat/hazard-vulnerability > is considered with the use of RRA, the related incidents can be presented to people who make the analysis. They can modify the preliminary assessment while taking into account the past events.

9. The presented methodology (a decision framework) is designed to be implemented in software. For this reason, an extra functionality in the software will be necessary. This is called the Common facility. The Common module consists of administration, user access control, management, and reporting functionalities.

It is possible to extend SUMAD RMT with two additional options in the future:

10. Revitalization decisions made by decision-makers, even when supported by DMAV, are still complicated. For this reason, an extra supporting tool based on the classical AHP concept is proposed. AHP allows for the assessment of considered RVAs with respect to the criteria based on the RRA/CBA/QCA analyses results.

11. The SUMAD project scope ends with the elaboration of the revitalization plan based on the selected RVA. To extend the tool in the future, a dedicated PES (Performance Evaluation Subsystem) can be proposed to monitor the revitalized object and to suggest its corrections and improvements. This issue is discussed in [7]. This PES can be integrated into a system which monitors the physical parameters of the revitalized object.

These two optional modules will not be discussed in this paper. The above-mentioned modules are shown on the UML (Unified Modelling Language) class diagram (Figure 1).

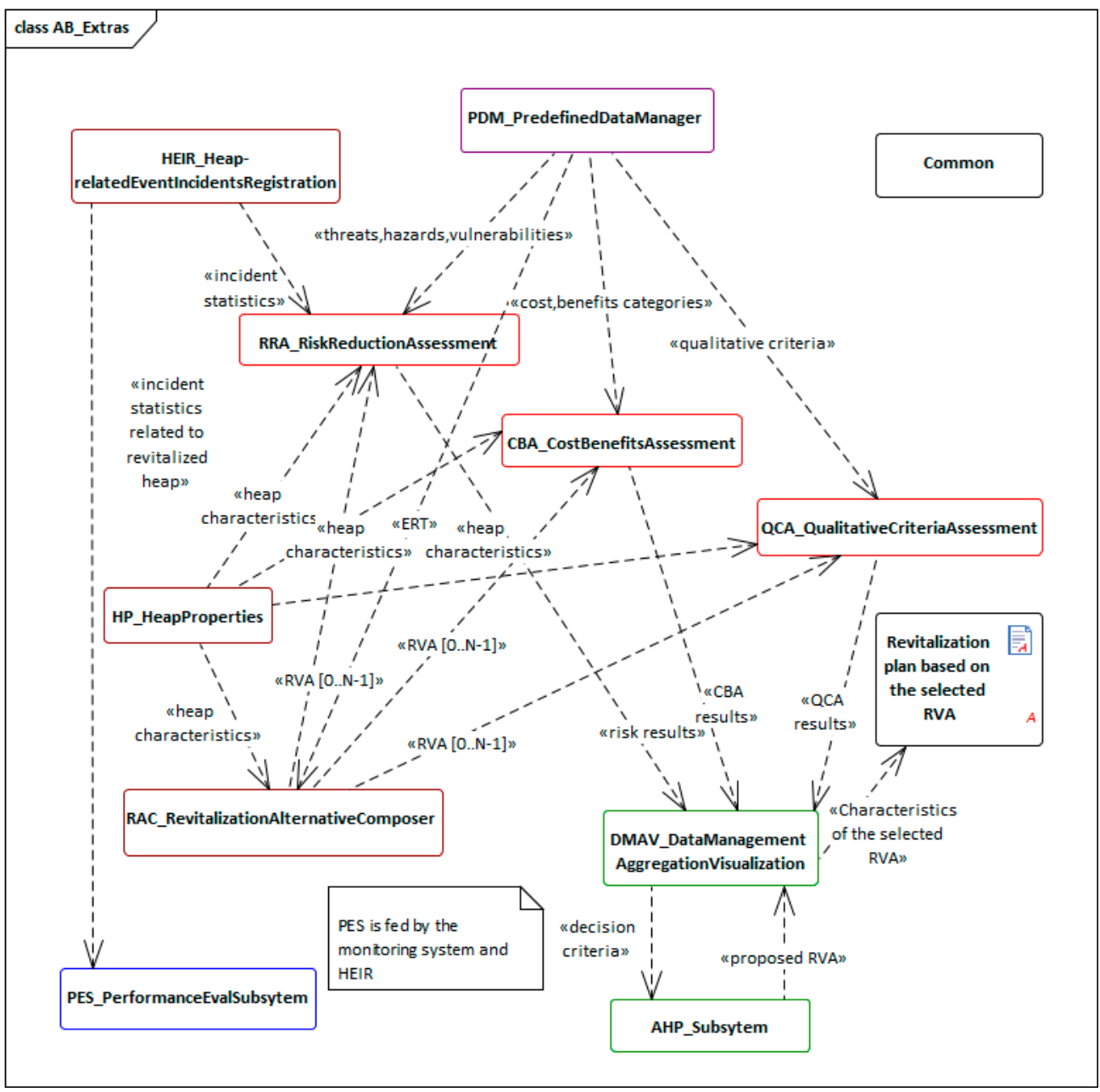

Figure 1. Functional blocks of the SUMAD RMT on the UML class diagram. 
The main analytical modules are RRA, CBA, and QCA. They are called "pillars" of the applied advanced risk management methodology. Revitalization techniques grouped in the revitalization alternatives play the role of "measures" in risk terminology. Revitalization alternatives are assessed with respect to the risk reduction ability (RRA), the cost-benefit assessment parameters (CBA), and different qualitative constraints and opportunities. Figure 1 specifies the kinds of information passed between functional blocks. PDM and HEIR include common data (knowledge base) for all managed projects. HP specifies a given heap to be an object of revitalization. To compose revitalization alternatives from elementary ERTs, RAC is designed. DMAV is a tool that directly supports decision-makers in selecting the most advantageous (risk, cost, constraints) alternative for implementation. Two other optional modules, PES and AHP, are not discussed in this paper. Figure 1 presents information flows in SUMAD RMT as well. The Common module will provide the basic functionality to manage the software and its users, i.e., establishing roles and the project team, managing operation logs, communications, reporting, etc.

\subsection{Common Knowledge Base}

SUMAD RMT will be able to manage many revitalization projects in the same domain of application. All these projects are based on very similar data. To manage and share these common data, two modules, PDM and HEIR, are developed.

\subsubsection{Common Knowledge Base of Incidents}

HEIR allows for the registration of heap-related incidents and the building up of statistics on this basis. Incidents are identified as threats/hazards during incident reporting. Knowledge related to their occurrences and impacts is used as a feedback for the risk analysis to reduce the uncertainty of assessments performed by risk analysts.

\subsubsection{Common Knowledge Base of Predefined Domain Data Dealing with Risk Factors}

PDM involves reusable domain data related to threats/hazards, vulnerabilities, revitalization techniques, cost-benefit categories, non-financial criteria, and utility functions (UF). Particular predefined items are shared upon demand from different, mostly analytical, modules of SUMAD RMT.

PDM includes numerous items considered to be threats/hazards, ordered by category and subcategory.

Threats/hazards to the heap include two categories:

- Environmental factors, including:

Atmospheric factors: cyclic heating, cyclic thawing, hailstorms, oversized rain or snow, air pollution, smog, etc.

Geological factors: slope instability, ground instability, earthquake, tremor, excessive rock pressure, erosion, discontinuous deformations, settlement, etc. Hydrological factors: internal drainage, acid rock drainage, cyclic drying/wetting, etc.

- Human actions:

Starting a fire: spontaneous combustion, smoldering waste, self-heating, bonfires, etc.

Littering: biodegradable or non-degradable objects (different kinds).

Material theft, e.g., coal, plants, soil.

Uncontrolled sport activities: motocross/quads racing, biking.

Threats/hazards to the heap environment include:

- Environmental physical threats:

Fire hazard to forests or buildings.

Explosion hazard.

Hydrological hazard: ground water pollution, surface water pollution, acid rock drainage, high salt wash-off, etc. 
- Pollution hazards:

Air pollution: carbon monoxide, bad smells.

Corrosive materials, e.g., chemicals, acids.

Ignitable materials.

Radioactive materials.

Toxic materials.

Examples of threats/hazards to the revitalization alternative are:

- Ground instability: landslides, gullies, wrong geometry of slopes, muddy flows, improper parameters of heap base materials.

- Combustion and fire-related factors: fire on the heap or its environment.

Threats/hazards to the revitalization alternative imply the kind of activity or facility for the revitalized heap. For example, for wind turbines placed on the heap, the following factors should be considered: failures such as blade throw, fire, icing, ice throw, etc.; for photovoltaic panels-fire should be considered.

Predefined vulnerabilities can be related to:

- Different kinds of surface or ground erosion,

- Heap instability caused by:

- Dynamic forces, e.g., blasting forces or seismic activity.

Foundation strengths: grain size, density, moisture, kind of materials, spoil depth.

- Ground and water condition: permeability, vegetation, topography, rainfall, drainage.

$\bigcirc \quad$ Spoil dump geometry.

Spoil strengths: creep, grain size, weathering, moisture.

- Fire and explosions.

- Water or soil pollution from materials or chemicals.

For risk scenarios, some attributes (keywords) describing consequence categories are predefined:

- Environmental impacts: air pollution, water pollution, dust, gas production, soil contamination, detrimental smells.

- Physical impacts: damage of buildings and technical infrastructure, landslides, discontinuous deformations, slope instability, changes in hydrological conditions, combustion of materials.

- Others, such as human casualties.

2.2.3. Common Knowledge Base of Predefined Domain Data Dealing with Revitalization Techniques

Elementary Revitalization Techniques (ERTs) are divided into two general categories:

- Material utilization (heap is considered a source of different materials to be used elsewhere), e.g., for levelling, concrete production, pavement construction, backfilling or stowing in mining, for railroad or road construction, dams.

- Land development (the heap will be left in its place but will be considerably improved and modified for future useful applications in business or for citizens), e.g.,

- Ground improvement: securing technical infrastructure, soil cleaning, pollution elimination, revegetation, communication and drainage systems.

- Hydrological improvement: alteration of drainage or flow management, plugged drains, construction of hydro-technical devices for biological treatment, agriculture, or forest reclamation.

Industrial application: photovoltaic installations, wind turbines, coal recovery, heat pumps, logistic storage, factory buildings, transport facilities.

- Agriculture and biodiversity application: animal farm, bee garden, biomass production.

- Applications for citizens: sport, residential buildings, recreation, cultural purposes. 
2.2.4. Common Knowledge Base of Predefined Domain Data Related to CBA Categories Three main categories for CBA are distinguished:

- CAPEX (CAPital EXpenditures), comprising:

Initial costs: bidding, preparing preliminary studies, licenses, personnel, training. Infrastructure costs: design and construction, installation, leasing.

Logistic costs: storage and transportation.

Maintenance costs: initial and spare parts.

Planning costs: design, experiments and tests, market research, project management, travel, personnel.

Procurement costs: equipment, service, construction, documentation.

Integration and setup costs related to equipment, services, personnel, subcontracting.

- OPEX (OPerating EXpenditures), consisting of:

$\bigcirc$ Direct costs: insurance, licenses, permits, logistic, subcontractors and services, safety and security.

Supplies: energy, water, communications.

Different kinds of economic losses related to business profits, image, customer acceptance, quality of life, theft.

End-of-life costs: disassembly, recycling, personnel.

$\bigcirc$ Different kinds of maintenance costs: equipment, facilities, services, personnel, spare parts, unscheduled activity.

- $\quad$ BENEFITS, including:

Direct benefits: value of produced energy, sold materials from the heap, entrance tickets, etc.

2.2.5. Common Knowledge Base of Predefined Domain Data Related to QCA Criteria and Utility Functions

Currently, nine groups of QCA categories, each with assessed criteria, are distinguished:

- Society-related: acceptance of revitalization activity, living conditions, changing behavior of local community, job quality, labor market, positive or negative emotions, education, knowledge, promotion of the municipality, social cohesion.

- Individual person-related: risks and opportunities for individuals, personal investments, physical health, mental health (well-being).

- Laws and regulations: law compliance, regulations for potential damage and other compensations, suitability.

- Rights and ethics: transparency, lawfulness, innovativeness and constructiveness, professionalism.

- Politics: complexity of decision processes, local election chances, international cooperation/effort, NGO compatibility, responsibility, trust, visibility, publicity, and democracy.

- Economics (indirect, externalities): chances of getting additional funds, sources of financing, business reputation or overall performance, general investment climate, economic stability, revenues, potential losses, value of local properties.

- Technology and science: scientific or technological development, standardization, usability of technology, availability of technology, dependency of technology, publicprivate partnerships, technical limitations, spatial conditions.

- Environment: aesthetics and sensual conditions (sight, smell, sound), climate conditions, hydrological conditions, natural environment, cultural environment, current land use, hidden/side effects, movements/mobility, waste management.

- General principles: applicability, feasibility, effectiveness, time efficiency.

PDM includes predefined utility functions (UF). Their shapes express the character of impact of the given criterion during the QCA assessment.

All PDM data can be easily modified or supplemented by new items on requests from people performing the analyses. Their versioning should be possible. 


\subsection{Management of the Revitalization Project}

Figure 2 presents how the given revitalization project is managed within this framework.

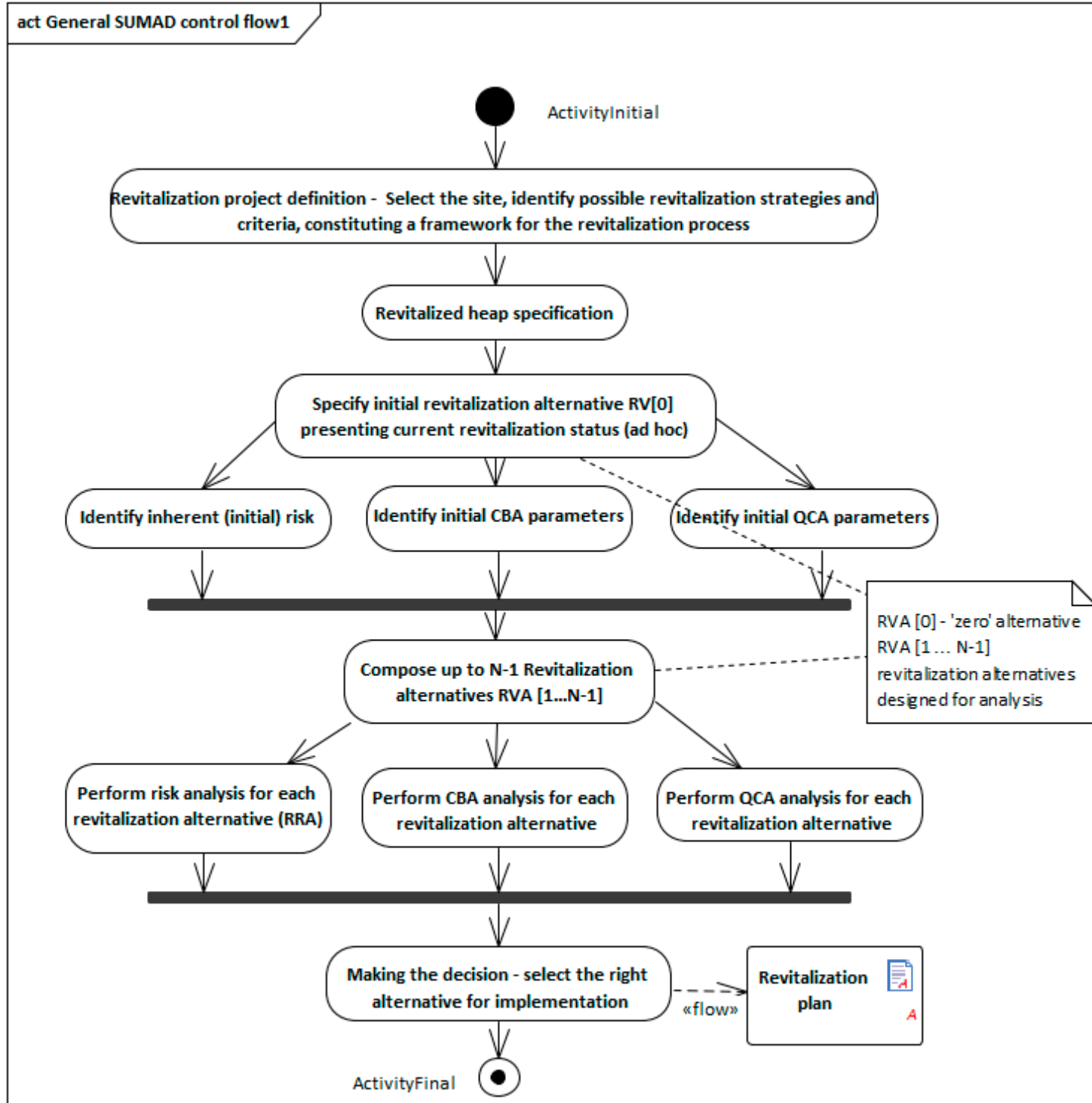

Figure 2. Planning of the heap revitalization process shown in the UML activity diagram.

The activities (steps) presented here are typical. No horizontal interactions between the RRA, CBA, QCA analytical components are needed. They work independently and provide their "aggregated results" to the higher layer (DMAV), where they are visualized to the decision-maker.

Please note that the presented methodology includes three main steps:

- Identification of the heap to be revitalized;

- Composing and analyzing the alternatives;

- Decision making.

All activities are presented below in separate sections. 


\subsubsection{The Revitalized Heap Specification}

The revitalization project deals with one heap and starts with an analysis of the stakeholders' needs and expectations related to future land use, technical requirements and constraints, legal and regulatory requirements, detailed identification of the heap and its environment, etc.

All this information is specified with the use of the HP module. As a result, a very detailed specification is elaborated, which includes:

- Administrative records containing owner, localization, etc.

- Geometrical parameters, including area height, volume, shape.

- Geological parameters, including age, critical water contents of fine-grained soil, consistency, particle size, compressibility, stiffness, cohesion, structure, kind of heap material, technical conditions, surface usability.

- Pollutants related to ignitability, corrosivity, radioactivity, reactivity, toxicity, littering, including bulky waste as well as biodegradable and non-degradable materials.

- Heap environment records, including landscape characterization, climate parameters, air pollution status, vegetation and animals (especially protected ones), surrounding water, protected areas such as culture heritage or nature.

Apart from these issues, the revitalization preconditions are specified, including:

- Legal restrictions.

- Revitalization actions launched up until now, usually ad hoc.

- Available financial, technical, and operational resources.

2.3.2. Identifying and Planning the Revitalization Alternatives

This task is performed twice:

- Before the risk analysis - to identify the current revitalization status (the so called "zero" alternative) prior to any planned actions.

- After the risk analysis-to propose means (ERTs) of reducing the identified risks caused by the heap.

The project team is able to identify any revitalization activity performed in the past as the "zero" alternative RVA(0), which will be a reference point for any planned revitalization activity. Revitalization alternatives are created with the use of the RAC facility. RV(0) and other RV(i) $(i=1 \ldots \mathrm{N}-1)$ have the same data representation, containing: the RV name, description, and the set of ERTs, downloaded from the PDM knowledge base (Section 2.2.3).

RVA(0) is a subject of the RRA, CBA, and QCA analyses.

\subsubsection{Preliminary Risk Analysis}

The general model of the RRA is shown in Figure 3. It is based on the consequence probability method [9].

Figure 3 includes a UML class model. A class represents an object or a set of objects with a common structure and behavior. They are represented by a rectangle whose rows are class names, attributes, and operations. The diagram shows the main RRA classes and the relationships between them (associations with roles and multiplicities, information flows). The risk analysis team focuses on the pairs $<$ threat/hazard-vulnerability $>$, called here risk scenarios, and assesses the related likelihood and consequences. As a result, the risk value is calculated as their product.

Threats/hazards and vulnerability items are predefined in the knowledge base (PDM) and the analysts (people performing the analysis) select the right pairs for analysis with respect to the characteristics of the heap and its environment. It was assumed that the threats and hazards categories are considered in the same way (Section 2.2.2). 


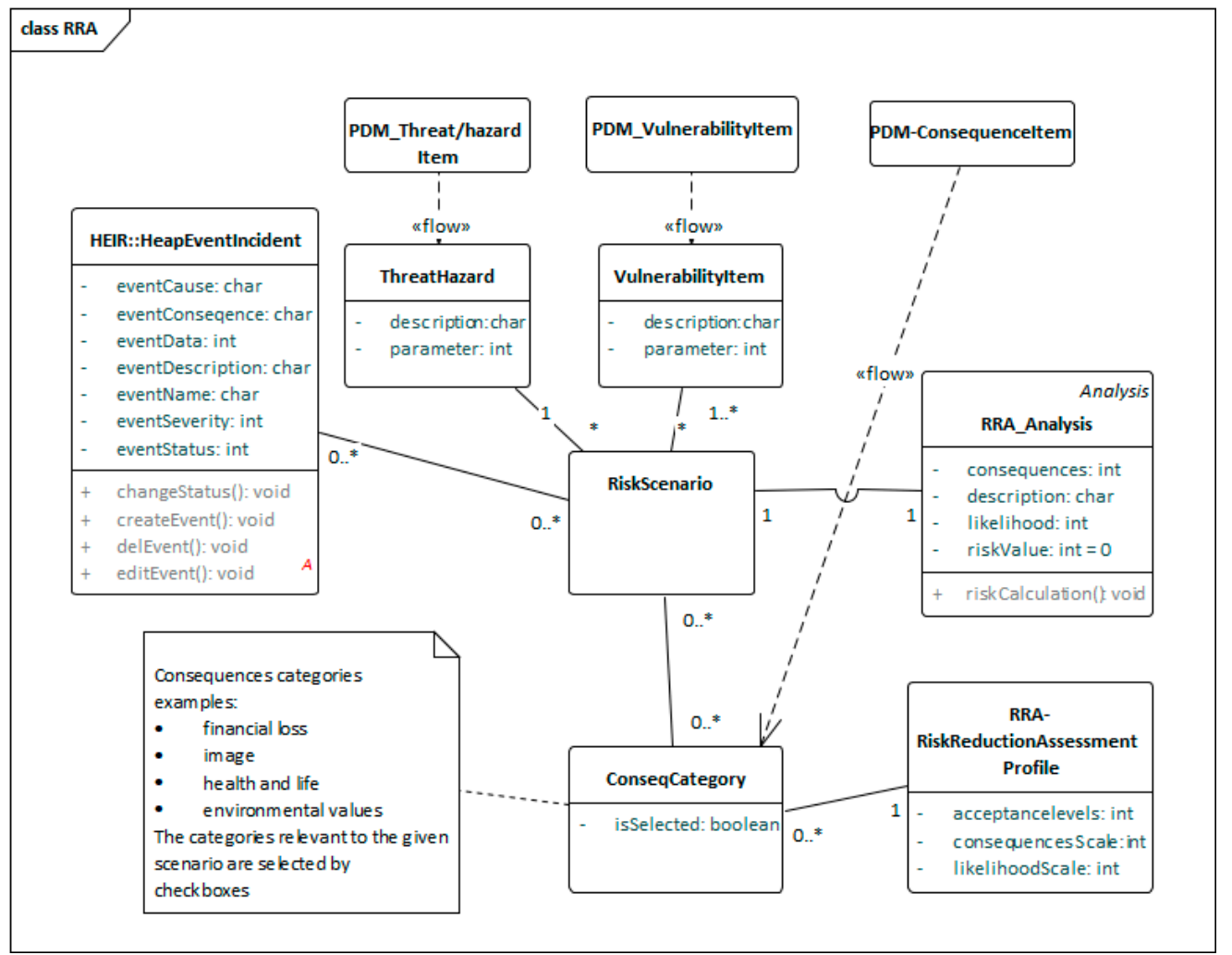

Figure 3. The RRA model on the UML class diagram. Symbol "*” means "any of" in multiplicities.

The RRA module is able to analyze risk factors for the heap, its environment, and those related to the revitalization alternatives (in both directions: from alternative to the heap and its environment, and vice versa).

Additionally, for each scenario, a textual description and some predefined attributes describing consequence categories may be added to refine this scenario. They play the role of keywords, which may be used to make relations between incidents and scenarios more precise.

The Likelihood (L) and Consequence (C) input parameters are expressed with the use of configurable scales: $\left(\mathrm{L}_{\min } \ldots \mathrm{L}_{\max }\right),\left(\mathrm{C}_{\min } \ldots \mathrm{C}_{\max }\right)$. It implies that risk value, calculated as $R V=L \times C$, is also expressed in the predefined scale: $\left(R V_{\min } \ldots R V_{\max }\right)$, where $\mathrm{RV}_{\min }=\mathrm{L}_{\min } \times \mathrm{C}_{\min }$, and $\mathrm{RV}_{\max }=\mathrm{L}_{\operatorname{ma}} \times \mathrm{C}_{\max }$.

The $\mathrm{L}, \mathrm{C}$ values are assigned by the people performing the risk analysis (usually through brain storming) on the basis of the characteristics of the heap, its environment, and optionally, the revitalization activity. Assessment scales have interpretations of particular enumerative values to decrease the subjectivity of assessments and to unify verdicts. Interpretations concern the range of losses in different categories (Figure 3): financial, image, health and life, environmental values, etc. The verdicts should be justified considering the scenario's context. All scales and interpretations are common for the revitalization project and are configured before the project is launched.

To increase the preciseness of the assessment verdicts (to reduce the assessment uncertainty), the HEIR facility (Section 2.2.1) may be helpful. As for the past incidents related to the considered scenario, their frequency and consequences may help the analyst to reduce the uncertainty of the assessed $\mathrm{L}$ and $\mathrm{C}$. There are relationships between incident records and risk scenarios in the proposed SUMAD methodology.

The RRA module is also used to assess risk related to the revitalized heap for any proposed alternatives.

The RRA analysis is focused on the given RVA coincidently with the heap characteristics. The risk reduction can be determined by comparing the risk value for RVA(i), (i >0), 
i.e., the residual risk, with the inherent risk value for $\mathrm{RV}(0)$. The $\mathrm{RVA}$ ability to reduce risk is a very important parameter of the decision-making process.

\subsubsection{Cost-Benefit Assessment}

Generally, a cost-benefit analysis is the process of comparing the projected or estimated costs and benefits (or opportunities) associated with a project decision to determine whether it makes sense from a business perspective [42].

Any revitalization project is considered from a certain business perspective. The CBA module provides financial information to decision-makers, allowing them to assess:

- The current financial status of the heap (cost, benefits), when basic, necessary, ad hoc activities were performed $(\operatorname{RVA}(0))$; it is a reference status;

- The financial status of the heap after the implementation of each planned revitalization alternative (RVA(i), $\mathrm{i}>0)$.

Comparing the financial parameters achieved by RVA(i) with the reference parameters $(\operatorname{RVA}(0))$, the decision-maker is provided with important information to select the right RVA(i) for implementation.

The CBA module of SUMAD RMT is based on the idea of the CBA tool elaborated by the ValueSec project team $[40,41]$, but it is adapted to quite a different domain of application.

The CBA framework looks similar to a matrix and is shown in Figure 4. The rows include three configurable groups of categories and subcategories (CAPEX, OPEX, and BENEFITS). The analyst selects and downloads these categories and subcategories from the PDM knowledge base according to his/her needs (Section 2.2.4). The columns represent a time span of the analysis and are partitioned into quarters or years. The analysis requires a setup of analytic parameters (currency, discount rate, budget, constraints) in the beginning.

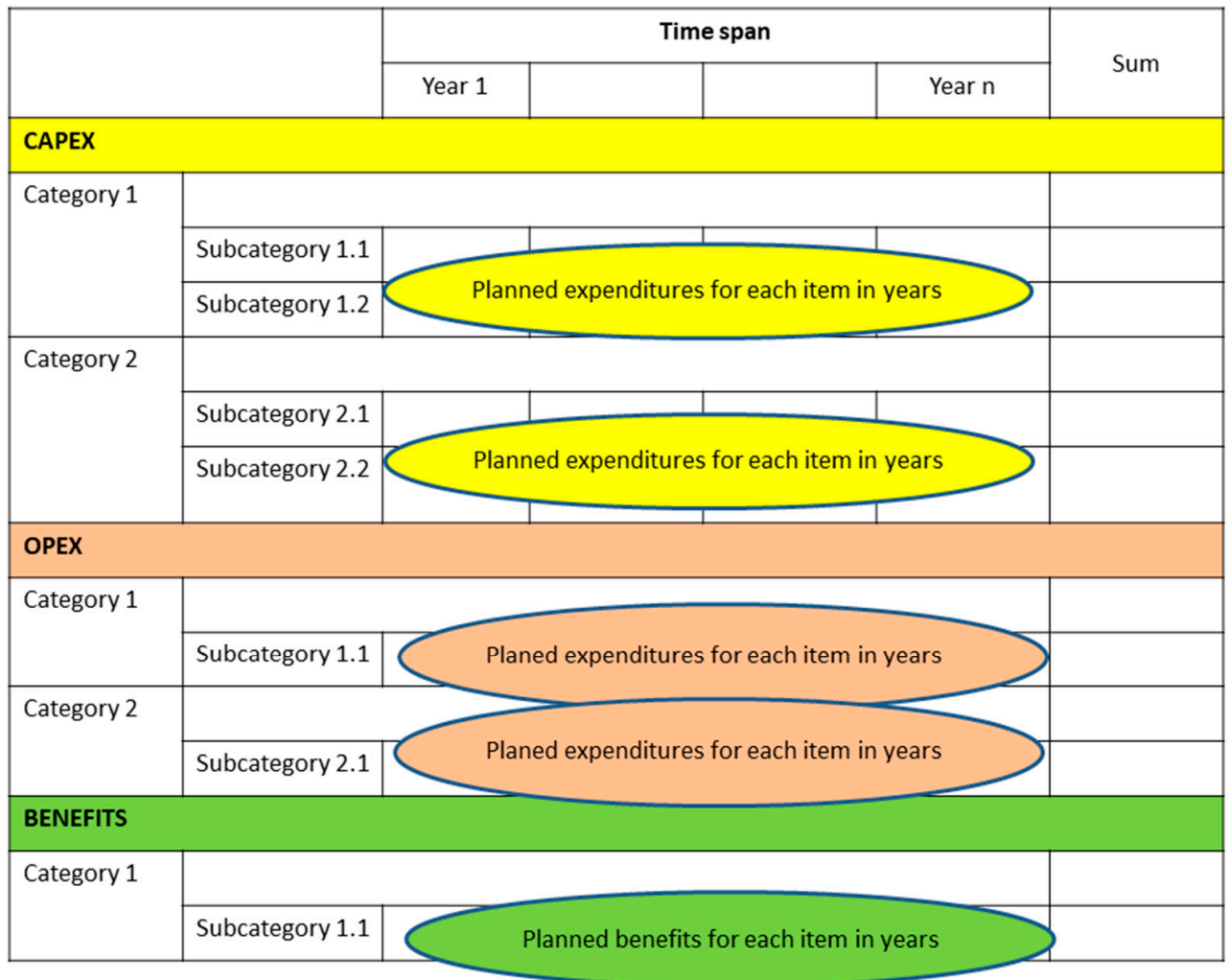

Figure 4. The CBA planning matrix for the given revitalization alternative. Groups of categories are marked with different colors. 
The CBA tool allows for the calculation of the different indicators related to the investment efficiency, such as the NPV (Net Present Value), BCR (Benefit Cost Ratio), or Pay Back Period. The analyst plans cost-benefit variables represented by categories in the time span and calculates these indicators. Sometimes he/she performs a sensitive analysis. Such analyses should be repeated for any RVA(i), where $i>=0$. It is difficult to obtain representative financial parameters for RVA(0). In this case, approximate lump sums are enough.

\subsubsection{Qualitative criteria assessment}

It is possible that the considered revitalization alternative is able to properly mitigate risk and has promising financial parameters, but it cannot be implemented due to social and political factors, among others, which reduce its effectiveness. These factors are assessed with the use of the qualitative criteria (QCA) module.

QCA provides non-financial information to decision-makers, allowing them to assess:

- The current constraints, opportunities related to the heap, for $(\operatorname{RVA}(0))$; it is a reference point;

- The constraints, opportunities concerning the heap after the implementation of each planned revitalization alternative (RVA(i), $\mathrm{i}>0)$.

Comparing the status (a set of parameters) achieved by RVA(i), (i>0) with the reference parameters $(\operatorname{RVA}(0))$, the decision-maker is provided with important information before selecting the right RVA for implementation (a target RVA).

The QCA framework is represented by the matrix, shown in Figure 5. The rows include groups of criteria (here: three groups). Each group may contain a certain number of criteria (here: three for Group 1, four for Group 2, and two for Group 3), which are assessed by the analyst. Each group has a weight assigned and the sum of the group weights should be $100 \%$. Similarly, each criterion belonging to the group has a group weight assigned, and their sum within the group should be $100 \%$ as well.

\begin{tabular}{|c|c|c|c|c|c|}
\hline & & $\begin{array}{l}\text { Group } \\
\text { weight }\end{array}$ & $\begin{array}{l}\text { Criteria } \\
\text { weight }\end{array}$ & Analyst assessment & Value for group \\
\hline \multicolumn{2}{|l|}{ Group 1} & $20 \%$ & & & Group 1 value \\
\hline & Criterion 1.1 & & $30 \%$ & & \\
\hline & Criterion 1.2 & & $40 \%$ & e.g. Positive & \\
\hline & Criterion 1.3 & & $30 \%$ & eutra & \\
\hline \multicolumn{2}{|l|}{ Group 2} & $45 \%$ & & & Group 2 value \\
\hline & Criterion 2.1 & & $25 \%$ & & \\
\hline & Criterion 2.2 & & $25 \%$ & Positive & \\
\hline & Criterion 2.3 & & $25 \%$ & Neutral & \\
\hline & Criterion 2.4 & & $25 \%$ & & \\
\hline \multicolumn{2}{|l|}{ Group 3} & $35 \%$ & & & Group 3 value \\
\hline & Criterion 3.1 & & $60 \%$ & & \\
\hline & Criterion 3.2 & & $40 \%$ & & \\
\hline \multicolumn{5}{|r|}{ Total for RVA } & RVA value \\
\hline
\end{tabular}

Figure 5. The QCA calculation table for the given revitalization alternative. Groups of criteria and their subgroups are marked with different colors. 
The analyst selects and downloads these groups from the PDM knowledge base and a certain number of criteria of each group according to his/her needs (Section 2.2.5).

After downloading the criteria, the analyst should properly configure weights. Next, he/she assigns verdicts using a predefined enumeration scale (e.g., Very negative I Negative I Neutral I Positive I Very positive). On the basis of verdicts and weights, values for each group are calculated as well as the total value (a sum) for the given RVA. Introduced verdicts are in red italics, obtained results in bold green italics. Additionally, each criterion has utility functions (UF) assigned. Utility functions in SUMAD are used to measure different kinds of preferences represented by qualitative criteria with respect to revitalization actions. They are also predefined in PDM. These UFs are used in the above-mentioned calculations, helping to express the character (linear, non-linear) of impact of the given criterion. Utility functions translate the qualitative characteristics of a criterion into a normalized scale. A value $x$ assigned by the analyst is an argument of UF. The value $y=U F(x)$ and the weight are used in calculations.

2.3.6. Establishing a Certain Number of Revitalization Alternatives and Assessing Their Properties with Respect to the "Zero" Alternative

After assessing RVA(0) with the use of RRA, CBA, and QCA, the analyst defines a certain number of revitalization alternatives that meet the revitalization strategy and consider the future land use. They are elaborated with the use of the RAC module in the same way as the $\operatorname{RVA}(0)$.

Each of them should be assessed with the use of RRA, CBA, and QCA, producing aggregated data for the decision-making process.

\subsubsection{Decision-Making and Issuing Revitalization Plan}

Generally, the most advantageous RVA should be useful and able to reduce the risk. It should generate with minimal costs, bring maximal benefits, be free of limitations, and be acceptable to people and stakeholders. The issue is how to identify this target RVA.

This decision is supported by the DMAV module, which allows for the aggregation and visualization of the most important data (parameters) from all analyses. These data are analyzed with respect to the revitalization objectives, constraints, and land use.

\section{SUMAD Risk Management Methodology Validation}

The SUMAD advanced risk management methodology that supports decision-makers should be validated before its implementation as the SUMAD RMT software tool.

In this paper, a simplified example of this validation is presented. An extensive and detailed validation is performed by the project consortium members.

The validation criteria can be expressed as follows:

Successfully performing all operations presented in Figure 2 and providing complete aggregated results of these operations for the decision-maker to allow him/her to select the target revitalization alternative for implementation, i.e., to perform the following operations:

- Heap properties identification;

- Initial RRA, CBA, QCA analyses related to current state;

- Proposing a certain number of revitalization alternatives for consideration;

- Assessing these alternatives with respect to the risk reduction (RRA), financial (CBA), and non-financial (QCA) parameters;

- Providing the aggregated data from the analyses to the decision-makers in order to select the target solution for implementation according to the assumed criteria.

The validation includes all relevant steps of the SUMAD RMT methodology presented in Section 2.3 with the use of data described in Section 2.2. 


\subsection{The Revitalized Heap Specification}

Let us assume a hypothetical heap (called $\mathrm{HH}$ ), described below. Its full identification, involving all properties mentioned in Section 2.3.1, cannot be presented here. In this paper, the author focuses on its summarized description and on its key properties.

Please note that some statements below have been tagged by a risk analyst. The risk analyst subsequently added some tags to the heap description during the RRA, CBA, and QCA analyses to identify essential information for these analyses. The following labels were used:

- $\quad\{$ ERT $i\}$ - because the statement implies, directly or indirectly, the given Elementary Revitalization Technique (see Sections 3.2 and 3.6);

- $\quad\{R S j\}$ - because the statement implies, directly or indirectly, the given Risk Scenario (RSj) (see Sections 3.3 and 3.6);

- $\quad\{\mathrm{CBA} k\}$-because the statement implies, directly or indirectly, the given cost or benefit categories (see Sections 3.4 and 3.6);

- $\quad\{Q C A l\}$ - because the statement implies, directly or indirectly, the given qualitative criteria (see Sections 3.5 and 3.6).

The heap properties can be expressed as follows:

The mining $\mathrm{HH}$ waste landfill, relatively young $\{\mathrm{RS} 3\}$, was established in the period 1986-2010.

The waste consistency is characterized as a mixture of roof rocks, floor rocks, coal overgrowth, and the vast majority are represented by: claystones, stigmaria soils, clay siderites, occasionally mudstones and-rarely—sandstones. The main heap materials are: gravel, loam, and shales and have rather poor geological parameters; $\{\mathrm{RS} 3\},\{\mathrm{RS} 7\},\{\mathrm{RS} 8\}$. On the east slope, a certain amount of coal waste is included; $\{\mathrm{RS} 5\},\{\mathrm{RS} 6\},\{\mathrm{RS} 9\}$.

The waste has the following shape parameters:

- Area: 90 (ha);

- Average angle of slope: from 1:3 to 1:6;

- Height: ca. $30(\mathrm{~m})$;

- Volume: 30 million $\left(\mathrm{m}^{3}\right)$.

$\mathrm{HH}$ is located in the zone where the concentrations of $\mathrm{SO}_{2}, \mathrm{NO}_{2}, \mathrm{CO}$, and benzene do not exceed the lower assessment threshold, while the concentration of PM10 dust is between the upper and lower assessment threshold.

The main pollutants are: water reactive materials such as $\mathrm{CaO}, \mathrm{MgO}, \mathrm{K}, \mathrm{Na}$, inorganic toxins such as $\mathrm{As}, \mathrm{Ba}, \mathrm{Pb}$, and organic toxins such as Carbon Tetrachloride, Chloroform $\{\mathrm{RS} 8\}$.

Rare vegetation, $\{R S 1\},\{R S 2\}$, includes the natural succession of shrubs and rushes. Wildlife mostly includes amphibians, land fowl, water fowl, and small herbivore mammals.

The surrounding water includes: an artificial watercourse reservoir flowing along the southern foot of the $\mathrm{HH}$, a drainage ditch running from $\mathrm{SW}$ to $\mathrm{NE}$, a small natural lake, a catchment of three small rivers.

The annual meteorological average data are:

- Wind: $2.0-5.3(\mathrm{~m} / \mathrm{s})$; dominant wind direction is south;

- Rainfall: 630 (mm); oversized rain during the summer, $\{\mathrm{RS} 2\},\{\mathrm{RS} 7\}$;

- Insolation: $1060-1110\left(\mathrm{kWh} / \mathrm{m}^{2}\right)$;

- Temperature: $8.1\left({ }^{\circ} \mathrm{C}\right)$; in this region, a high amplitude of annual temperatures is observed $\{$ RS1\}.

The agricultural landscape exists around $\mathrm{HH}$, with a small share of forest communities. On the eastern side of the heap, $600 \mathrm{~m}$ from its edge, there are residential buildings of farms, magazines, railway, local roads, and further, a shopping center. There are no cultural heritage objects within the zone experiencing the environmental impact. Sometimes, illegal moto-crossing is organized, $\{$ RS4 $\}$. 
Limited past revitalization actions include:

- Ad hoc partial afforestation, soil cleaning $\{$ ERT1\}, $\{$ ERT2\},

- Levelling of degraded areas, concrete production \{ERT3\}.

\subsection{Identifying Current Revitalization Activities}

Regarding the above heap description, $\operatorname{RVA}(0)$ is composed of the following ERTs, shown in Table 1. It is the "zero" alternative.

Table 1. RVA(0)—Current revitalization activities.

\begin{tabular}{cc}
\hline Label & Elementary Revitalization Techniques \\
\hline ERT1 & Decreasing the heap volume by ca. $10 \%$ and using this material for \\
levelling the external degraded areas and for concrete production \\
ERT2 & Partial afforestation \\
ERT3 & Experimental soil cleaning \\
\hline
\end{tabular}

\subsection{Preliminary Risk Analysis (RRA)}

This analysis concerns inherent risk related to the heap in the current state, with some ad hoc revitalization actions already accomplished-comprising the RVA(0) alternative.

Let us assume the predefined scales for the risk assessment:

- $\quad$ For Likelihood (L):

1. Nearly impossible;

2. Low;

3. High;

4. Almost certain.

- For Consequences (C):

1. Negligible;

2. Low;

3. High;

4. Critical.

This means that the Risk Value $\mathrm{RV}=\mathrm{L} \times \mathrm{C}$ is in the range from 1 to 16 . Let us assume that:

- $\quad \mathrm{RV}$ from 1 to 3 is "Acceptable" risk—it will be marked green;

- $\quad \mathrm{RV}=4$ or 6 or 8 is "Tolerable" (usually monitored)—marked yellow;

- $\mathrm{RV}=9$ or 12 or 16 is "Unacceptable" (should be mitigated)—marked red.

Table 2 presents a certain number of risk scenarios, RSj, and their assessment (inherent risk, which deals with $\mathrm{RV}(0)$ ). These scenarios are identified by the risk analyst on the basis of the heap description.

In Table 2, some simplifications are applied with respect to the designed SUMAD RMT:

- Justifications of the L, C verdicts are omitted; the above $\mathrm{L}$ and $\mathrm{C}$ measurement scales are very general because they should match any risk scenario; to raise the preciseness in the designed software, the $L$ and $C$ verdicts should be precisely justified/interpreted in the context of a given risk scenario and heap properties (including physical parameters), which requires deep domain knowledge from the analyst; for such cases, different but relevant factors should be taken into account: the frequency of events/phenomena, impacted areas or assets, exposition to a threat, motivation of the threat agent, etc.;

- Support by the HEIR module; to decrease the uncertainty in the designed software, the analyst can review past incidents related to this risk scenario (frequency, consequences). 
Generally, nine scenarios were identified:

- Four were "Unacceptable", $44 \%$ of scenarios;

- Three were "Tolerable", 33\% of scenarios;

- Two "Acceptable", 22\% of scenarios.

Table 2. Preliminary (inherent) risk analysis—an exemplification.

\begin{tabular}{|c|c|c|c|c|c|c|}
\hline Label & Threat/Hazard & Vulnerability & $\mathbf{L}$ & $\mathrm{C}$ & $\mathbf{R}$ & Impact \\
\hline \multicolumn{7}{|c|}{ Risk scenarios concerning the heap } \\
\hline RS1 & Cyclic heating & Vuln. to surface erosion & 3 & 2 & $6^{1}$ & Heap surface deformation \\
\hline RS2 & Oversized rain & Vuln. to splash erosion & 3 & 3 & 9 & Slope deformation \\
\hline RS3 & Settlement & $\begin{array}{l}\text { Low geotechnical } \\
\text { parameters }\end{array}$ & 3 & 4 & 12 & Instable heap surface \\
\hline RS4 & $\begin{array}{l}\text { Quads/motor } \\
\text { racing }\end{array}$ & Uncontrolled access & 3 & 4 & 12 & $\begin{array}{l}\text { Slope instability } \\
\text { Landslides } \\
\text { Human casualties }\end{array}$ \\
\hline RS5 & Smoldering & Coal availability & 1 & 2 & 2 & $\begin{array}{c}\text { Detrimental smells and a nuisance to } \\
\text { nearby residents }\end{array}$ \\
\hline RS6 & Material theft & Coal availability & 4 & 4 & 16 & $\begin{array}{l}\text { Uncontrolled destruction of slopes } \\
\text { or surface }\end{array}$ \\
\hline \multicolumn{7}{|c|}{ Risk scenarios concerning the heap environment } \\
\hline RS7 & Cyclic wetting & Water permeability & 1 & 4 & 4 & $\begin{array}{l}\text { Subsidence basins around the heap } \\
\text { Increased soil moisture, } \\
\text { Increased 1st aquifer }\end{array}$ \\
\hline RS8 & Toxic materials & Water permeability & 2 & 3 & 6 & $\begin{array}{c}\text { Landfill leachate containing } \\
\text { dangerous substances } \\
\text { Groundwater pollution }\end{array}$ \\
\hline RS9 & Starting a fire & $\begin{array}{l}\text { Coal availability-possible } \\
\text { spontaneous combustion } \\
\text { from coal }\end{array}$ & 1 & 1 & 1 & $\begin{array}{l}\text { Burning down the buildings } \\
\text { around the heap }\end{array}$ \\
\hline
\end{tabular}

${ }^{1}$ Unacceptable risks are marked red. Tolerable risks are marked yellow. Acceptable risks are marked green.

\subsection{Preliminary Cost-Benefit Analysis (CBA)}

The CBA analysis for RVA(0) is specific and is based on historical financial data. It can be performed roughly because usually, there are no complete historical data. It is focused on identifying the lump sums related to the main cost categories and to the benefits, if such exist. CBA is exemplified in Figure 6, which also shows the analyses for RVA(1) and RVA(2), discussed later.

The first column specifies some examples of categories and subcategories for CAPEX/ OPEX/BENEFITS, downloaded from the knowledge base by the analyst as relevant for the given revitalization project. For RVA(0), some values are identified (in the used currency).

With respect to the risk analysis methodology, these cost-benefit values deal with "the existing measures" when inherent risk is analyzed.

This CBA preliminary assessment improves the coherency of the SUMAD RMT methodology and identifies a reference level to define other alternatives. 


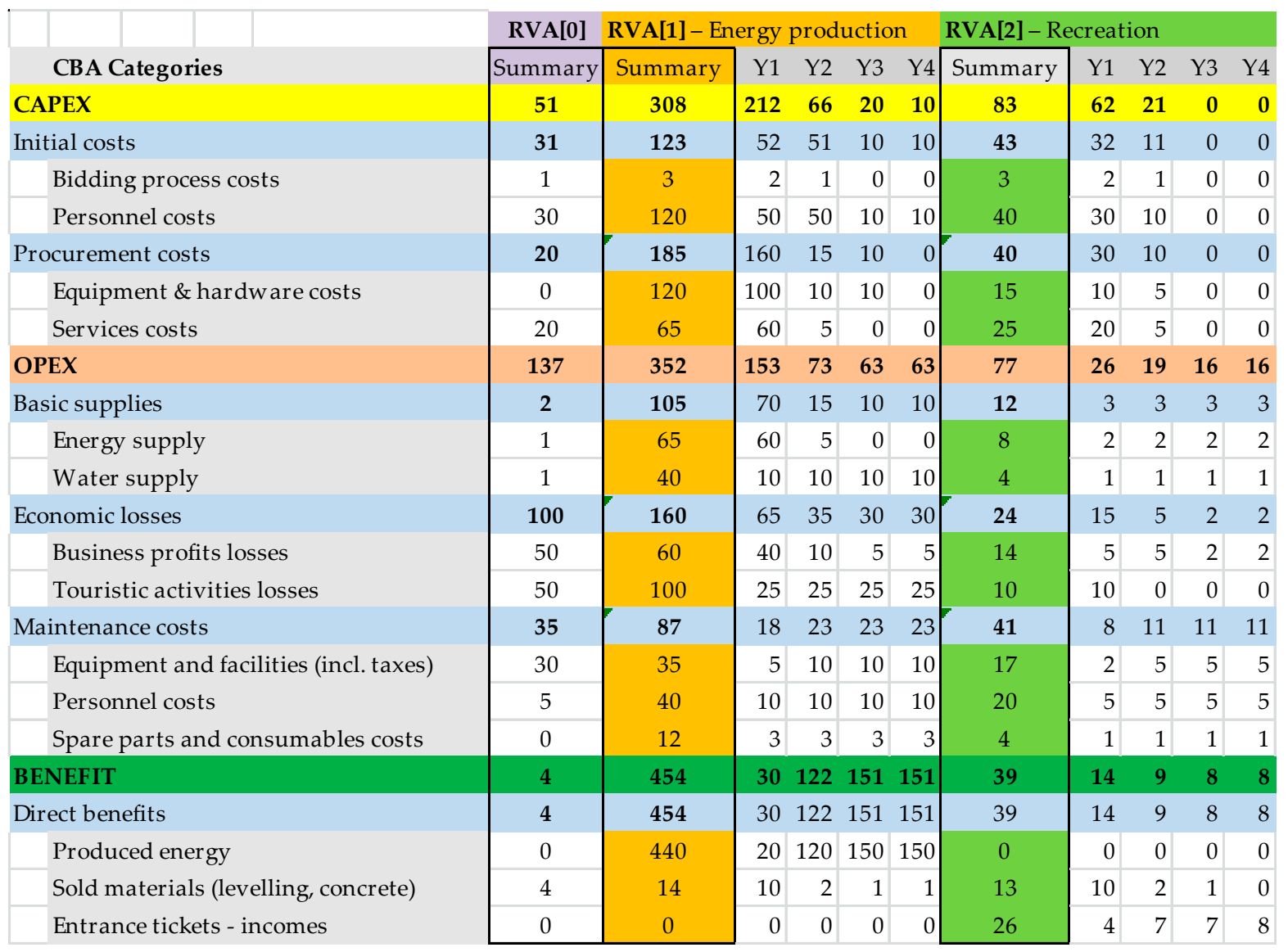

Figure 6. Cost-benefit analysis-an exemplification. The rows include three configurable groups of categories and subcategories (CAPEX-marked yellow, OPEX marked salmon pink and BENEFITS marked green). Apart from the names of the CBA categories, three revitalization alternatives are placed vertically: the simplified RVA(0)—-marked violet, and the planned ones: RVA(1)—marked orange, and RVA(2) - marked light green. Each of them has a bordered column with the summary of values with respect to the category/subcategory. Both planned alternatives RVA(1), RVA(2) have their time horizons, showing how the financial values are planned.

\subsection{Preliminary Qualitative Criteria Analysis (QCA)}

The objective of the preliminary QCA analysis is to assess non-tangible factors related to the heap revitalized according to $\operatorname{RVA}(0)$.

The utility functions (UF) are important in the qualitative assessment. For each criterion, the analyst can assign the right utility function, predefined in the knowledge base. UFs are used to model the linear or non-linear impact character expressed by the given criterion. Different UF1-UF6 examples are shown in Table 3. The analyst can select the right functions for the given criteria. He/she can also configure output values according to his / her needs.

QCA is exemplified in Figure 7, which also shows the QCA analyses for RVA(1) and RVA(2), discussed later. In the example presented in Figure 7, all criteria use the UF1 defined in Table 3. 
Table 3. UF definitions-examples.

\begin{tabular}{|c|c|c|c|c|c|c|}
\hline Input Value & UF1 Output & UF2 Output & UF3 Output & UF4 Output & UF5 Output & UF6 Output \\
\hline High negative & -10 & -10 & -10 & & & \\
\hline Medium negative & -5 & -7 & -5 & & & \\
\hline Low negative & -2 & -3 & -2 & & & \\
\hline Neutral & 0 & 0 & 0 & 0 & & \\
\hline Low positive & 2 & 1 & & 2 & & \\
\hline Medium positive & 5 & 2 & & 5 & & \\
\hline High negative & 10 & 3 & & 10 & & \\
\hline Yes & & & & & 10 & 0 \\
\hline No & 1 & & & & 0 & -10 \\
\hline UF type & $\begin{array}{l}\text { Symmetrical } \\
\text { positive } \\
\text { / negative } \\
\text { impact of the } \\
\text { criterion }\end{array}$ & $\begin{array}{l}\text { Asymmetrical } \\
\text { positive } \\
\text { /negative } \\
\text { impact of the } \\
\text { criterion }\end{array}$ & $\begin{array}{l}\text { Used when } \\
\text { only negative } \\
\text { impact exists }\end{array}$ & $\begin{array}{l}\text { Used when } \\
\text { only positive } \\
\text { impact exists }\end{array}$ & $\begin{array}{l}\text { Positive } \\
\text { yes/no } \\
\text { criterion }\end{array}$ & $\begin{array}{l}\text { Negative } \\
\text { yes/no } \\
\text { criterion }\end{array}$ \\
\hline
\end{tabular}

${ }^{1}$ empty cell-not applicable for this UF.

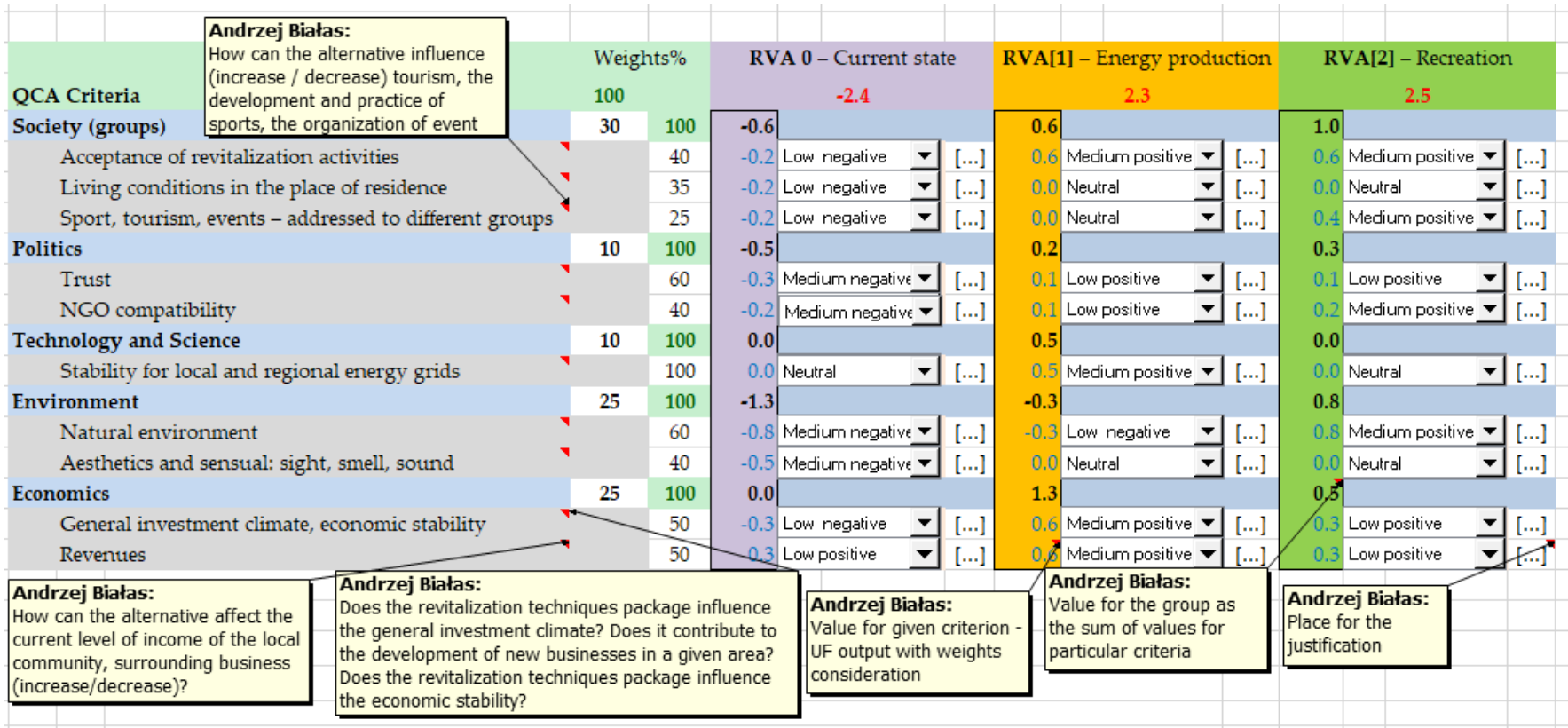

Figure 7. Qualitative criteria analysis—an exemplification. The first column presents the QCA groups of criteria (marked blue) and their criteria (marked grey). To the right of them, the weights for groups and particular criteria are placed. Next, three revitalization alternatives are placed vertically: RVA(0) — marked violet, RVA(1) — marked orange, and RVA(2) — marked light green. Each of them has a bordered column with the utility function outputs summarized by groups. On the right side of the bordered columns the utility functions inputs are presented as enumeration values. Further to the right, there is a place for justification. Some hints and explanations for the analyst are presented as well.

For this project, the analyst downloads five groups with relevant criteria: Society (groups), Politics, etc. They are shown in column 1.

Next, he/she assigns weights (Figure 7) to groups (their sum should be 100\%) and weights to particular criteria in each group (the sum should also be $100 \%$ ). The weights represent the criteria importance in the given project.

The input value (an assessment) assigned by the analyst is mapped by UF1 to the output value, which is multiplied by the group and the criterion weights, obtaining the assessed value for the considered criterion. 
For example (Figure 7), "Acceptance of revitalization activities"(related to RVA(0)) is assessed by the analyst as "Low negative". This value is mapped by UF1 to -2 , multiplied by the group weight (30\%) and by the criterion weight $(40 \%)$, which results in the criterion value -0.2 (rounded -0.24). Values are summarized within groups (for the "Society" group, it is -0.6$)$. The sum of values for all groups gives the aggregated value for RVA(0), i.e., -2.4 (marked red). This means that current revitalization efforts are assessed negatively.

3.6. Establishing a Certain Number of Revitalization Alternatives and Assessing Their Properties with Respect to the "Zero" Alternative Using RRA, CBA, and QCA

After the preliminary RRA, CBA, and QCA analyses, the analyst has a general picture of the inherent risk, current cost-benefit parameters, and non-tangible factors. It allows him/her to elaborate a certain reasonable number of revitalization alternatives for further consideration, leading to the selection of the target for implementation. The proposed revitalization alternatives should:

- Mitigate at least "Unacceptable" risks;

- Be in line with the assumed land use, business needs, citizens' expectations, natural environment, etc.;

- $\quad$ Be feasible (considering financial and non-financial constraints).

In the example presented in the paper, two Revitalization Alternatives are defined; the first is focused on energy production $(\operatorname{RVA}(1))$, the second on recreation purposes (RVA(2)). They are shown in Table 4.

Table 4. Proposed revitalization alternatives.

\begin{tabular}{|c|c|c|}
\hline ERT. & Influenced RS & Elementary Revitalization Techniques \\
\hline \multicolumn{3}{|c|}{$\begin{array}{c}\text { Common Elementary Revitalization Techniques-risk mitigation and heap } \\
\text { improvement and adaptation }\end{array}$} \\
\hline ERT4 & RS5, RS6, RS9 & Coal recovery (from the eastern slope) \\
\hline ERT5 & RS4,RS6 & Fence, access control \\
\hline ERT6 & RS8 & Permanent control of the release of toxic substances \\
\hline ERT7 & RS8, RS3 & Soil cleaning, ground improvement \\
\hline ERT8 & RS1, RS2 & Revegetation, afforestation \\
\hline ERT9 & RS7 & $\begin{array}{c}\text { Modification of hydraulic conditions (drainage, flow } \\
\text { management, pipeline) }\end{array}$ \\
\hline ERT10 & RS2 & Profiling slopes and their monitoring \\
\hline \multicolumn{3}{|c|}{ RVA(1) - Renewable energy production } \\
\hline ERT1-1 & & $\begin{array}{l}\text { Establishing the technical infrastructure (roads, media, } \\
\text { buildings, etc.) for energy production facilities }\end{array}$ \\
\hline ERT1-2 & & Photovoltaic installation on the south slope \\
\hline ERT1-3 & & Wind turbines on the top area of the heap \\
\hline ERT1-4 & & Energy network, equipment \\
\hline ERT1-5 & & Greenery around \\
\hline ERT1-5 & & Reinforced foundation \\
\hline \multicolumn{3}{|r|}{ RVA(2)-Recreation purposes } \\
\hline ERT2-1 & & $\begin{array}{l}\text { Establishing the relevant technical infrastructure (roads, media, } \\
\text { buildings, etc.) for recreation facilities, small hotel, parking, } \\
\text { restaurant, facilities for musical events }\end{array}$ \\
\hline ERT2-2 & & Park around \\
\hline ERT2-3 & & Bicycle racing tracks \\
\hline ERT2-4 & & Didactic trips \\
\hline ERT2-5 & & Ski tracks \\
\hline ERT2-6 & & Photovoltaic installation for internal use \\
\hline ERT2-7 & & Fire protection and monitoring \\
\hline
\end{tabular}


It was assumed that both alternatives are based on the revitalization activities ERT1, ERT2, and ERT3 performed in the past; both have the same set (a simplification for the paper) of ERTs (ERT4-ERT10) for the risk mitigation, improvement, and adaptation to target applications. The relevant risk scenarios are enumerated, e.g., ERT4 is applied to reduce the risks concerning RS5, RS6, and RS9.

The risk analysis is performed again (compared to Table 2), and its results are shown in Table 5. First, the common risk scenarios are analyzed, considering the proposed ERT4ERT10. The ERTs play the role of risk reduction measures.

Table 5. Residual risk consideration—an exemplification.

\begin{tabular}{|c|c|c|c|c|c|c|c|}
\hline \multicolumn{8}{|c|}{ Common Risk Scenarios } \\
\hline RS & ERT & Threat/Hazard & Vulnerability & $\mathbf{L}$ & $\mathrm{C}$ & $\mathbf{R}$ & Comments \\
\hline \multicolumn{8}{|c|}{ Risk scenarios concerning the heap } \\
\hline RS1 & ERT8 & Cyclic heating & Vuln. to surface erosion & $3 \rightarrow 2$ & $2 \rightarrow 1$ & $6 \rightarrow 2^{1}$ & Revegetation, afforestation \\
\hline RS2 & $\begin{array}{l}\text { ERT10 } \\
\text { ERT8 } \\
\text { ERT9 }\end{array}$ & Oversized rain & Vuln. to splash erosion & $3 \rightarrow 2$ & $3 \rightarrow 2$ & $9 \rightarrow 4$ & $\begin{array}{l}\text { Slopes improved/monitored, } \\
\text { revegetation, afforestation, } \\
\text { improved hydr. conditions }\end{array}$ \\
\hline RS3 & $\begin{array}{l}\text { ERT7 } \\
\text { ERT9 }\end{array}$ & Settlement & $\begin{array}{l}\text { Low geotechnical } \\
\text { parameters }\end{array}$ & $3 \rightarrow 2$ & $4 \rightarrow 3$ & $12 \rightarrow 6$ & $\begin{array}{l}\text { Additional measures for } \\
\text { specific facilities (buildings, } \\
\text { wind turbines) required }\end{array}$ \\
\hline RS4 & $\begin{array}{l}\text { ERT5 } \\
\text { ERT10 }\end{array}$ & Quads/motor racing & Uncontrolled access & $3 \rightarrow 1$ & $4 \rightarrow 1$ & $12 \rightarrow 1$ & $\begin{array}{l}\text { Access control } \rightarrow \text { no races, } \\
\text { slopes improved } / \text { monitored }\end{array}$ \\
\hline RS5 & ERT4 & Smoldering & Coal availability & 1 & $2 \rightarrow 1$ & $2 \rightarrow 1$ & $\begin{array}{l}\text { Almost no coal } \rightarrow \text { no smells } \\
\quad \text { (additional mitigation) }\end{array}$ \\
\hline RS6 & $\begin{array}{l}\text { ERT4 } \\
\text { ERT5 }\end{array}$ & Material theft & Coal availability & $4 \rightarrow 1$ & $4 \rightarrow 1$ & $16 \rightarrow 1$ & $\begin{array}{l}\text { Almost no coal } \rightarrow \text { no } \\
\text { opportunities for theft, fence, } \\
\text { access control }\end{array}$ \\
\hline \multicolumn{8}{|c|}{ Risk scenarios concerning the heap environment } \\
\hline RS7 & ERT9 & Cyclic wetting & Water permeability & 1 & $4 \rightarrow 3$ & $4 \rightarrow 3$ & $\begin{array}{l}\text { Hydrological conditions } \\
\text { improved }\end{array}$ \\
\hline RS8 & $\begin{array}{l}\text { ERT7 } \\
\text { ERT9 }\end{array}$ & Toxic materials & Water permeability & $2 \rightarrow 1$ & $3 \rightarrow 2$ & $6 \rightarrow 2$ & $\begin{array}{l}\text { Soil and hydrological } \\
\text { conditions improved }\end{array}$ \\
\hline RS9 & ERT4 & Starting a fire & $\begin{array}{l}\text { Coal } \\
\text { availability-possible } \\
\text { spontaneous } \\
\text { combustion from coal }\end{array}$ & 1 & 1 & 1 & $\begin{array}{l}\text { No fire related to coal } \\
\text { (additional mitigation) }\end{array}$ \\
\hline \multicolumn{8}{|c|}{ Risk scenarios specific for RVA(1) } \\
\hline RS1-1 & ERT1-5 & $\begin{array}{l}\text { The weight of the } \\
\text { structure, i.e., of the } \\
\text { wind turbine masts and } \\
\text { other heavy structures }\end{array}$ & $\begin{array}{l}\text { Reduction in material } \\
\text { properties of spoil base } \\
\text { materials }\end{array}$ & $3 \rightarrow 1$ & $4 \rightarrow 3$ & $12 \rightarrow 3$ & $\begin{array}{c}\text { Mast overturning, } \\
\text { destructions, human } \\
\text { casualties (RVA } \rightarrow \text { Heap) }\end{array}$ \\
\hline RS1-2 & ERT1-5 & $\begin{array}{c}\text { The weight of the } \\
\text { structure, i.e., of the } \\
\text { photovoltaic equipment } \\
\text { on the slope }\end{array}$ & $\begin{array}{l}\text { Adverse effect of the } \\
\text { geometry (slope angle) }\end{array}$ & $3 \rightarrow 1$ & $3 \rightarrow 3$ & $9 \rightarrow 3$ & $\begin{array}{c}\text { Landslides, destruction of PV } \\
\text { equipment, fire (RVA } \rightarrow \\
\text { Heap) }\end{array}$ \\
\hline \multicolumn{8}{|c|}{ Risk scenarios specific for RVA(2) } \\
\hline RS2-1 & ERT2-7 & Fire on the heap & $\begin{array}{l}\text { Vuln. to fire, esp. when } \\
\text { drought occurs, many } \\
\text { people around }\end{array}$ & $3 \rightarrow 2$ & 2 & $6 \rightarrow 4$ & Fire (RVA $\rightarrow$ Heap) \\
\hline RS2-2 & ERT2-7 & Fire outside the heap & $\begin{array}{l}\text { Vuln. to fire, esp. when } \\
\text { drought occurs, many } \\
\text { people around }\end{array}$ & $3 \rightarrow 2$ & 2 & $6 \rightarrow 4$ & Fire (RVA $\rightarrow$ Heap) \\
\hline
\end{tabular}

${ }^{1}$ Tolerable risks are marked yellow. Acceptable risks are marked green. Arrow means that thanks to the ERT8, the risk value is reduced from 6 to 2 . 
Considering nine scenarios of inherent risk identified in Table 2, the risk picture is positively changed (residual risk), thanks to the application of ERT4-ERT10:

- None were "Unacceptable", $0 \%$ of scenarios;

- Two were "Tolerable", 22\% of scenarios;

- $\quad$ Seven were "Acceptable", 73\% of scenarios.

Next, only two scenarios specific for RVA(1) and RVA(2) are identified and analyzed (a simplification for the paper). In each case, two kinds of impacts can be considered: Heap to RVA, RVA to Heap and environment.

Let us consider RVA(1). The most serious scenarios for this RVA are:

- $\quad$ RS1-1 (risk value = 12, “Unacceptable”);

- $\quad$ RS1-2 (risk value = 9, “Unacceptable”).

Both risks can be mitigated by applying reinforced foundations (ERT1-5) to reach a value of 3, "Acceptable".

Let us consider RVA(2). The most serious scenarios to this RVA are related to fire, especially during drought:

- $\quad$ RS2-1 (risk value =6, "Tolerable");

- $\quad$ RS2-2 (risk value =6, "Tolerable").

Both risks can be mitigated by applying fire protection and monitoring (ERT2-7), to reach a value of 4 (also "Tolerable", but lower).

Only the most serious risks related to RVA are considered above.

Next, the CBA analysis should be applied to each of the alternatives as well in order to assess the profitability of investments related to the revitalization process. This was exemplified for RVA(1) and RVA(2) in Figure 6. The analysis is performed in a certain time horizon (here, only for four years) considering the budget constraints and financial parameters such as the discount rate. The analyst plans cost and benefits in time, calculates financial indicators such as the NPV, and makes a sensitivity analysis. In Figure 6, it is shown that RVA(1) generates more cost and benefits than RVA(2). A more detailed analysis should be possible in SUMAD RMT, such as the NPV, sensitivity, etc.

In addition, the QCA analyses are applied to every alternative to assess positive and negative non-financial impacts from the given RVA. In Figure 6, some analyses for RVA(1) and RVA(2) are presented. Compared to RVA(0), which was assessed negatively $(-2.4)$, both RVA(1) and RVA(2) are positive (2.3, 2.5-respectively), but due to different reasons expressed by the particular criteria; see details in Figure 6.

\subsection{Decision Making and Selecting the Most Advantegous Alternative-A Foundation for the Revitalization Plan}

To select the target RVA for implementation, the decision-maker should be provided with aggregated information from all analyses. He/she will then compare the values of parameters between alternatives and against the RVA(0) parameters (revitalization yield). These values are used as the selection criteria. The examples of such criteria are presented in Table 6.

Notes on the validation results:

1. Generally, both alternatives properly reduce inherent risks, and residual risks should be monitored.

2. The SUMAD risk management methodology allows for a consideration of risks related to the revitalization process. They should be mitigated as well by supplementary technical measures such as the ERT1-5 (Reinforced foundation), ERT2-7 (Fire protection).

3. With respect to the risk parameters, both alternatives are comparable.

4. The CBA results show that RVA(1) Energy production is a bigger investment than RVA(2) Recreation. It is more costly, but the expected benefits are considerably higher. Roughly calculated, NPV shows that NPV $<0$ (non-profitable), but there is a chance to get NPV $>=0$ (profitable) in a longer time horizon, e.g., in Year 8. The NPV analysis needs extra consideration beyond the scope of this paper. The RVA(2) investment has 
a rather "public" character. There is no chance to get NPV $>=0$, because permanent costs are higher than benefits. It needs permanent financial support.

5. Instead of this, $\operatorname{RVA}(2)$ is more valuable for citizens and the natural environment. This is envisaged by the QCA parameters.

6. The decision-maker can select the target alternative for the implementation or he/she can define other alternatives for assessment, e.g., a hybrid one.

The validation criteria mentioned at the beginning of this chapter assume that all activities (Figure 2) should be performed and the aggregated results should be worked out. The validation example confirms that all operations within the framework are performed successfully and results are provided.

Table 6. Aggregated information for the decision-maker.

\begin{tabular}{|c|c|c|c|}
\hline Criteria (Aggregated Parameters) & $\begin{array}{c}\text { RVA(0) } \\
\text { Current } \\
\text { Revitalization } \\
\text { Activities }\end{array}$ & $\begin{array}{c}\text { RVA(1) } \\
\text { Energy } \\
\text { Production }\end{array}$ & $\begin{array}{c}\text { RVA(2) } \\
\text { Recreation }\end{array}$ \\
\hline \multicolumn{4}{|l|}{ Risk-related parameters } \\
\hline No. of identified risk scenarios & 9 & 11 & 11 \\
\hline No. of “Unacceptable” risks & 4 & 0 & 0 \\
\hline No. of "Tolerable" risks & 3 & 2 & $2+2$ \\
\hline No. of "Acceptable" risks & 2 & $7+2$ & 7 \\
\hline Max. risk value & 16 & 6 & 6 \\
\hline Min. risk value & 1 & 1 & 1 \\
\hline \multicolumn{4}{|l|}{ Other defined by analyst } \\
\hline \multicolumn{4}{|l|}{ Cost-benefit parameters } \\
\hline Total investment cost (CAPEX) & 51 & 308 & 83 \\
\hline Total operational cost (OPEX) & 137 & 352 & 77 \\
\hline Total benefits & 4 & 454 & 39 \\
\hline NPV & - & $-10^{1}$ & $-30^{1}$ \\
\hline \multicolumn{4}{|l|}{$\begin{array}{c}\text { Other selected by analyst, } \\
\text { e.g., payback period }\end{array}$} \\
\hline \multicolumn{4}{|l|}{ Qualitative assessment parameters } \\
\hline QCA aggregated value & -2.4 & 2.3 & 2.5 \\
\hline Society (groups) & -0.6 & 0.6 & 1.0 \\
\hline Politics & -0.5 & 0.2 & 0.3 \\
\hline Technology and Science & 0.0 & 0.5 & 0.0 \\
\hline Environment & -1.3 & 0.3 & 0.8 \\
\hline Economics & 0.0 & 1.3 & 0.5 \\
\hline Other selected by analyst & & & \\
\hline
\end{tabular}

${ }^{1}$ Fictitious values; NPV $>=0$ for profitable investments.

\section{Discussion and Conclusions}

The heap revitalization process should be based on the risk assessment because each heap containing a spoiled ground generates many risks-for itself, for the people living around it, for business facilities, and for the natural environment. For this reason, it was assumed that the developed methodology should be able to mitigate risk by proposing revitalization actions appropriate to the risk character and value.

For the given heap, there usually exist many revitalization possibilities, and the revitalization budget is usually very limited. To consider this issue, it was assumed that the elaborated methodology should include methods similar to those used in economics to assess the profitability of an investment. Revitalization is a specific investment.

The revitalization of heaps influences many and sometimes contradictory interests of numerous and different stakeholders. It evokes a lot of positive or negative emotions and different expectations. Such factors should also be included in the elaborated methodology. 
It was mentioned in Chapter 1 that the heap revitalization issue is similar to those solved earlier in the ValueSec and CIRAS projects, but in quite different domains. ValueSec was based on three pillars (risk, cost-benefit, and soft factor assessment); for SUMAD, these three pillars are also proposed, but they have quite a different character and have to be worked out from scratch.

The author's contribution is related to the adoption of the advanced risk management methodology elaborated in the ValueSec project to the new application domain, i.e., the revitalization of heaps. This idea was included in the SUMAD proposal and is now subject for implementation by the SUMAD project team.

Please note that the proposed advanced risk management methodology supporting decision-makers in planning the heap revitalization should take into account various factors including:

- A detailed specification of the revitalized object; this was achieved by the predefined data structure, including administrative records, geometrical and geological parameters, pollutants, and the heap environment; they are included in the HP (Heap property) data structure; in the validation example, HP was used to describe a hypothetical heap that was simple but of diversified characteristics (Section 3.1); with respect to the general risk management methodology, heaps are considered "assets" requiring protection;

- A detailed specification of the revitalization actions; to achieve this, the revitalization alternatives were defined as sets (packages) of elementary revitalization techniques; the "zero" alternative is specific because it contains historical actions on the heap, such as removing ad hoc problems; other alternatives representing different visions of the revitalized heap in the future are subject for RRA, CBA, and QCA assessments in order to provide information to the decision-maker, who selects one of them as the target alternative for implementation; the validation examples show how the revitalization alternatives are composed; "RVA(0)—Current revitalization activities" were shown in Table 1, while "RVA(1)—Renewable energy production" and "RVA(2)—Recreation purposes" were in Table 4; to manage the revitalization alternatives, a special software module RAC was designed; by analogy to the general risk management methodology, the revitalization alternatives represent packages of elementary protection measures;

- $\quad$ Risk analysis; the RRA module is used to analyze the risk for RVA(0) and for other defined alternatives; it allows the decision-maker to assess the ability of particular candidate alternatives to mitigate risk; different kinds of risks are considered; it was exemplified in Table 2 (inherent risk) and Table 5 (residual risk for the considered alternatives);

- Cost-benefit assessment; the CBA module is used to assess different categories of incurred costs and benefits obtained for the particular candidate alternatives with reference to historical cost-benefit values assessed for RVA(0); it allows the decision-maker to assess which alternative is the most advantageous from the economic perspective; this was presented in Section 3.4, Section 3.6, and in Figure 6;

- Qualitative assessment of intangible factors dealing with revitalization; the QCA module is used to assess these factors with the use of elaborated qualitative criteria, applied to particular candidate alternatives, with reference to the results obtained for RVA $(0)$; it allows the decision-maker to assess which alternative is the most advantageous (perceived positively by people, individuals, conducive to the environment, etc.); this was presented in Section 3.5, Section 3.6, and Figure 7;

- Presentation of aggregated results from analyses to the decision-maker; the DMAV module is responsible for presenting ordered information to the decision-maker, allowing for a selection of the target alternative for implementation; this was exemplified in Table 6, which features a set of basic indicators.

The validation confirms that the presented methodology encompasses the whole procedure of planning the heap revitalization process. Its complexity justifies the development of the software tool, allowing for the management and reuse of revitalization project data, the performance of analyses, and the presentation of results to the decision-maker. The 
tool, called SUMAD RMT, is compliant with this methodology and is an example of the adoption of ICT to the revitalization domain.

The validation leads to some conclusions related to tool development:

- The tool should ensure rich data visualization and reporting facilities, not only for the RRA, CBA, and QCA analytical modules, but primarily for DMAV as the main module of the decision-maker;

- The tool should be able to manage many different revitalization projects based on the common knowledge base and functionality;

- Some extension in the future should be considered (outside the SUMAD project) to better support decisions, to monitor the revitalized objects, etc.;

- The tool's adaptation to a broader range of applications should be considered, e.g., revitalization of brownfields, abandoned military areas, industrial objects, etc.

Summing up, the research questions were solved in the following way:

1. Structurization of the decision process (data and operations). The general concept of the tool was elaborated and presented in Section 2.1. Particular components such as RRA, CBA, QCA, RAC, HP, etc. and their properties are implied by the stakeholders' needs. Figures 1 and 2 present how these components collaborate with each other. Section 2.3 features all operations leading to work out the aggregated information that allows for the selection of the target revitalization alternatives by decision-makers. Input information for decision-makers are worked out by the RRA, CBA, and QCA analytical components. Decision criteria examples are proposed in Section 3.7. Only the basic, tabular way of data presentation for the decision-maker is proposed in the paper. Table 6 shows criteria against revitalization alternatives. Graphical presentations are out of this paper's scope; these will be solved later by software designers. The knowledge base specifying predefined and reusable data categories is discussed in Section 2.2. The main data structure representing the revitalized heap properties and other data to be implemented within the tool components are discussed in Section 2.3.

2. Heap property specification. Domain experts are usually provided with extensive, informal, textual materials (reports) describing the heap to be revitalized. A very simplified example of such textual description, prepared for the purpose of this paper, is included in the Section 3.1. Such information should be structured to be useful for software application. For this reason the general structure, containing categories and subcategories of the heap properties, is proposed in Section 2.3.1. It is an initial version. Further development will be performed by the project team. The structure has an open character and should eventually be able to express different kinds of heaps. All heap properties sampled in one place in the tool are used by analysts as the input for the RRA, CBA, QCA analyses and for the composition of revitalization alternatives.

3. Specification of the SUMAD risk management framework for software developers. The application of UML, broadly used by software developers, solves this issue. Only a few examples of the UML diagrams were presented in the paper (Figures 1-3). The full design has been worked out by the project team. It will include more diagrams (such as case, class, activity, sequence, component, and architecture diagrams) as a typical software design.

Solving these issues allows us to refer to the research objectives defined in this paper:

1. The SUMAD risk management methodology (a framework) involves all steps necessary and sufficient to make decisions related to the target revitalization alternative. These steps include heap property identification, initial RRA, CBA, QCA analyses related to the current state, composing a certain number of revitalization alternatives for consideration, assessment of these alternatives with respect to risk reduction, financial and non-financial parameters, and providing aggregated data from analyses to decision-makers in order to select the target solution for implementation according 
to the assumed criteria. Their feasibility was confirmed by the simple validation presented in Chapter 3.

2. The SUMAD risk management methodology (a framework) allows the user to consider the different heap properties (geotechnical and environmental), heap-related risk factors, and economic and non-economic constraints. It was also confirmed by the simple validation presented in Chapter 3.

3. Owing to data and process structurization exemplified in the validation example, software developers obtain input information for their design. The use of UML allows for common understanding, further development, and software implementation.

As a result, the validated concept of the advanced risk management methodology was elaborated, which is currently implemented in the SUMAD RMT tool.

The general concept of the methodology validation presented in the paper is the basis for broader validation on a real heap recently launched by the project participants.

The paper presents a validated concept of an innovative tool supporting decision making in the revitalization of different kinds of the post-mining heaps. The tool allows users:

- To specify the heap properties on a very detailed level;

- To identify the current heap revitalization status;

- To define a certain number of revitalization alternatives for consideration;

- To assess them with respect to risk, financial, and non-financial factors;

- To elaborate the aggregated results of these analyses as the input for decision-makers who select target alternatives for implementation.

The literature review confirms that there are no ready-made risk management tools meeting these broad requirements. This concept meets the SUMAD project requirements (Section 1.2).

Funding: This research was partially funded by the EU Research Fund for Coal and Steel, grant agreement No. 847227, and partially by the author's organization: Institute Łukasiewicz-EMAG. The APC was funded by Institute Łukasiewicz-EMAG.

Institutional Review Board Statement: Not applicable.

Informed Consent Statement: Not applicable.

Data Availability Statement: All data are included in the paper.

Acknowledgments: The author wishes to thank Barbara Flisiuk for the language verification of this paper.

Conflicts of Interest: The author declares no conflict of interest. The funders had no role in the design of the study; in the collection, analyses, or interpretation of data; in writing the manuscript, or in the decision to publish the results.

\section{References}

1. SUMAD Web Page. Available online: http://www.sumad.info/ (accessed on 12 January 2022).

2. Ziemba, E. Sustainability Driven by ICT Adoption within Households, Enterprises, and Government Units. Procedia Comput. Sci. 2021, 192, 2279. [CrossRef]

3. Jaenicke, M. “Green growth": From a growing eco-industry to economic sustainability. Energy Policy 2012, 48, 13. [CrossRef]

4. ValueSec. Available online: https://cordis.europa.eu/project/rcn/97989/factsheet/en (accessed on 11 December 2021).

5. CIRAS. Available online: http:/ / cirasproject.eu/ (accessed on 11 December 2021).

6. Bialas, A. Risk Management Approach for Revitalization of Post-Mining Areas. Theory and Applications of Dependable Computer Systems. In Proceedings of the Fifteenth International Conference on Dependability of Computer Systems DepCoS-RELCOMEX, Brunów, Poland, 29 June-3 July 2020; Zamojski, W., Mazurkiewicz, J., Sugier, J., Walkowiak, T., Kacprzyk, J., Eds.; Advances in Intelligent Systems and Computing; Springer: Cham, Switzerland, 2020; Volume 1173, pp. 71-81. [CrossRef]

7. Bialas, A. Improving Effectiveness of the Risk Management Methodology in the Revitalization Domain. In Theory and Engineering of Dependable Computer Systems and Networks, Conference DepCoS-RELCOMEX 2021, Brunow, Poland, 28 June-2 July 2021; Zamojski, W., Mazurkiewicz, J., Sugier, J., Walkowiak, T., Kacprzyk, J., Eds.; Advances in Intelligent Systems and Computing; Springer: Cham, Switzerland, 2021; Volume 1389. [CrossRef] 
8. ISO 31000:2009; Risk Management-Principles and Guidelines. International Organization for Standardization ; International Electrotechnical Commission: Geneva, Switzerland, 2009.

9. ISO/IEC 31010:2009; Risk Management-Risk Assessment Techniques. International Organization for Standardization ; International Electrotechnical Commission: Geneva, Switzerland, 2009.

10. ENISA. Inventory of Risk Management/Risk Assessment Methods and Tools. Available online: https://www.enisa.europa.eu/to $\mathrm{pics} /$ threat-risk-management/risk-management/current-risk/risk-management-inventory (accessed on 11 December 2021).

11. Rausand, M. Risk Assessment: Theory, Methods, and Applications; Series: Statistics in Practice (Book 86); Wiley: Hoboken, NJ, USA, 2011.

12. Whitman, M.E.; Mattord, H.J. Management of Information Security, 6th ed.; Cengage: Boston, MA, USA, 2019.

13. Hokstad, P.; Utne, I.B.; Vatn, J. (Eds.) Risk and Interdependencies in Critical Infrastructures: A Guideline for Analysis; Springer Series in Reliability Engineering; Springer: London, UK, 2012. [CrossRef]

14. Fargašová, A. Ecological Risk Assessment Framework. Acta Environ. Univ. Comen. 2016, 24, 10-16. [CrossRef]

15. Kowalska, A.; Grobelak, A.; Kacprzak, M.; Lyng, A. Methods and tools for environmental technologies risk evaluation: The principal guidelines-A review. Int. J. Environ. Sci. Technol. 2021, 18, 1683-1694. [CrossRef]

16. U.S. Environmental Protection Agency (EPA). Guidelines for Ecological Risk Assessment; EPA: Washington, DC, USA, 1998.

17. TRIAD Web Page. Available online: https://triadcentral.clu-in.org/ (accessed on 11 December 2021).

18. U.S. Environmental Protection Agency (EPA). Mine Site Cleanup for Brownfields Redevelopment-A Three-Part Primer; EPA: Washington DC, USA, 2005. Available online: https://semspub.epa.gov/work/HQ/718145.pdf (accessed on 12 January 2022).

19. Crumbling, D.M. Summary of the Triad Approach; U.S. Environmental Protection Agency (EPA): Washington, DC, USA, 2004.

20. Zhu, Y.; Shi, L.; Hipel, K.W.A. The Identification of Risk Factors in Brownfield Redevelopment: An Empirical Study. In Proceedings of the 2012 IEEE International Conference on Systems, Man, and Cybernetics, Seoul, Korea, 14-17 October 2012. [CrossRef]

21. Mahammedi, C.; Mahdjoubi, L.; Booth, C.A.; Butt, T.E. Framework for preliminary risk assessment of brownfield sites. Sci. Total Environ. 2022, 807, 25-33. [CrossRef]

22. Chen, S.; Chen, B.; Fath, B.D. Ecological risk assessment on the system scale: A review of state-of-the-art models and future perspectives. Ecol. Model. 2013, 250, 25-33. [CrossRef]

23. Power, M.; McCarty, L.S. Trends in the Development of Ecological Risk Assessment and Management Frameworks. Hum. Ecol. Risk Assess. 2002, 8, 7-18. [CrossRef]

24. Hope, B.K. An examination of ecological risk assessment and management practices. Environ. Int. 2006, 32, 983-995. [CrossRef]

25. Mikhailov, V.; Koryakov, A.; Mikhailov, G. Ecological risk management in coal mining and processing. J. Min. Sci. 2015, 51, 930-936. [CrossRef]

26. Sobotka, A.; Radziejowska, A. Risk Analysis in the Realization of Buildings in Revitalized Areas. Arch. Civil Eng. J. Pol. Acad. Sci. 2019, 3, 113-126. [CrossRef]

27. Glenn, W.; Sutter, I.I. Ecological Risk Assessment, 2nd ed.; CRC Press Taylor \& Francis Group: London, UK, 2019.

28. Gruiz, K.; Meggyes, T.; Fenyvesi, E. (Eds.) Engineering Tools for Environmental Risk Management: 4. Risk Reduction Technologies and Case Studies; CRC Press Taylor \& Francis Group: London, UK, 2019.

29. Swedish Geotechnical Society. Risk Management in Geotechnical Engineering Projects-Requirements. Methodology; SGF Report 1:2014E (English Version, Translated in 2017); SGF: Linköping, Sweden, 2017.

30. Sondermann, W.; Kummerer, C. Geotechnical opportunity management-subsoil conditions as an opportunity and a risk. In Proceedings of the XVI Danube-European Conference on Geotechnical Engineering, Skopje, Republic of Macedonia, 7-9 June 2018; pp. 395-400.

31. Mishra, R.K.; Janiszewski, M.; Uotinen, L.K.T.; Szydlowska, M.; Siren, T.; Rinne, M. Geotechnical Risk Management Concept for Intelligent Deep Mines. Procedia Eng. 2017, 191, 361-368. [CrossRef]

32. Keyvanfar, A.; Shafaghat, A.; Mohamad, S.; Abdullahi, M.M.; Ahmad, H.; Mohd Derus, N.H.; Khorami, M. A Sustainable Historic Waterfront Revitalization Decision Support Tool for Attracting Tourists. Sustainability 2018, 10, 215. [CrossRef]

33. Spanidis, P.-M.; Roumpos, C.; Pavloudakis, F. A Multi-Criteria Approach for the Evaluation of Low Risk Restoration Projects in Continuous Surface Lignite Mines. Energies 2020, 13, 2179. [CrossRef]

34. Pavloudakis, F.; Roumpos, C.; Karlopoulos, E.; Koukouzas, N. Sustainable Rehabilitation of Surface Coal Mining Areas: The Case of Greek Lignite Mines. Energies 2020, 13, 3995. [CrossRef]

35. Al Heib, M.; Cherkaoui, A. Assessment of the Advantages and Limitations of Installing PV Systems on Abandoned Dumps. Mater. Proc. 2021, 5, 68. [CrossRef]

36. SMARTe Web Page. Available online: http://www.neptuneinc.org/smarte (accessed on 11 December 2021).

37. Vega, A.; Argus, R.; Stockton, T.; Black, P.; Black, K.; Stiber, N. SMARTe: An MCDA Approach to Revitalize Communities and Restore the Environment. In Decision Support Systems for Risk-Based Management of Contaminated Sites; Marcomini, A., Suter, G., Critto, A., Eds.; Springer: Boston, MA, USA, 2009. [CrossRef]

38. Khumpaisal, S.; Chen, Z.; Mulliner, E. A New Approach to assess risks in Urban Regeneration Project. In Proceedings of the 3rd International Academic Consortium for Sustainable Cities Symposium, At Faculty of Architecture and Planning, Thammasat University, Bangkok, Thailand, 15 June 2012. [CrossRef] 
39. Cellini Riegg, S.; Kee, J.E. Cost-Effectiveness and Cost-Benefit Analysis, In Handbook of Practical Program Evaluation; Newcomer, K.E., Hatry, H.P., Wholey, J.S., Eds.; Wiley: Hoboken, NJ, USA, 2010; Available online: https://d1wqtxts1xzle7.cloudfront.net/381266 36/CelliniKee21-with-cover-page-v2.pdf?Expires=1645166548\&Signature=X8zbpkjjWWz-awWT1P9EeXY9bsdYXzv717E3 1TB ZvsaPHeILQwvKXEoM-az2BujwzKEyY buKaxMYoMDJSM2nILBkjmB6WXECH TyrqzuvBSsR204NJrOxPUD1 NX-m74VB 6OU4ved7xwEdckS 1VcZE190P-n31yn5eB2i1gsu2NXp2wSB-Vq1EI9BHh2oicVfHSxI2X KE2jc8ak4C5A3Ladp84rDZsDpZHbF wCSgkwN2WD2GU aphCBZkYw5z01JA7XvDJFQG4-mvFGvBDqQ9vTOCT-ghXrc-fjlaoeTW0YimWhLzGf87KAP7UG-AW gHu7fxwGVH31JJ5c0CQQ_\&Key-Pair-Id=APKAJLOHF5GGSLRBV4ZA (accessed on 27 October 2015).

40. Adar, E.; Blobner, C.; Hutter, R.; Pettersen, K. An extended Cost-Benefit Analysis for evaluating Decisions on Security Measures of Public Decision Makers. In Proceedings of the 7th International Conference on Critical Infrastructure Security, Lillehammer, Norway, 17-19 September 2012.

41. Bialas, A. Cost-benefits aspects in risk management. Pol. J. Manag. Stud. 2016, 14, 28-39. Available online: https:// pjms.zim.pcz.p 1/resources / html/article/details?id=156835 (accessed on 1 September 2021). [CrossRef]

42. Stobierski, T. How to Prepare a Budget for an Organization: 4 Steps, Harvard Business School Online. Available online: https:/ / online.hbs.edu/blog/post/cost-benefit-analysis (accessed on 22 November 2021). 